\title{
The gp41 epitope, QARVLAVERY, is highly conserved and a potent inducer of IgA that neutralizes HIV-1 and inhibits viral transcytosis
}

\author{
S Jain ${ }^{1}$ and KL Rosenthal ${ }^{1}$
}

Mucosal surfaces are the predominant site of human immunodeficiency virus (HIV)-1 transmission. For prophylactic approaches to effectively prevent HIV infection and subsequent dissemination, the induction of mucosally relevant protective immunity will be critical. Here, we have characterized the antibody (Ab) response generated by a highly conserved gp41epitope, QARVLAVERY, in an optimized immunization model that elicits potent epitope-specific Abs in the serum, vaginal washes, and fecal secretions of immunized mice. Our results show that QARVLAVERY is indeed a potent inducer of IgA and importantly, QARVLAVERY-specific IgA was effective in neutralizing HIV and inhibiting viral transcytosis. Intriguingly, QARVLAVERY also generated an approximate 1:1 ratio of IgG:IgA in the serum of immunized mice, independent of the delivery regimen and produced early systemic IgA, even before IgG. In light of the significantly high IgA induction by QARVLAVERY and the functionality of epitope-specific Abs in the inhibition of HIV infection and transcytosis, QARVLAVERY is an attractive epitope to be considered in mucosal vaccination strategies against HIV.

\section{INTRODUCTION}

The development of a prophylactic vaccine that generates potent cross-clade immunity against HIV is critical for effectively curbing the global human immunodeficiency virus (HIV)/AIDS (acquired immunodeficiency syndrome) pandemic. HIV is primarily a sexually transmitted infection, and in women, the majority of new infections occur through the urogenital tract. It is well accepted that strengthening mucosal defenses against virus entry, viral transmission, and infection will need to be addressed by prophylactic approaches. Thus far, this goal has met with several challenges, the greatest being the enormous diversity of HIV-1, which makes the generation of long-term immunity against it a constantly moving target.

At large, antibodies (Abs) generated during acute and chronic HIV infection are not effective in neutralizing the virus. ${ }^{1,2}$ In addition, a majority of the rare neutralizing Abs (nAbs) that are detected in natural infection tend to target nonconserved regions of the envelope and are quickly rendered ineffective because of rapid mutation of the virus. ${ }^{3,4}$ Clinical vaccines based on envelope antigens have thus far been unsuccessful in inducing long-term cross-reactive Ab responses. 5,6
T cell-based vaccine approaches in simian models and in clinical cohorts have also eventually succumbed to the emergence of viral escape mutants. ${ }^{7-10}$ These past lessons have stressed the importance of eliciting effective and broad immunity against conserved targets of HIV, to prevent and control its infection despite the genetic diversity.

The identification of broadly reactive human monoclonal Abs such as 2F5, 4E10, 2G12, 1b12, VRC01, HJ16, and PG9/16, ${ }^{11-15}$ against gp120/gp41 motifs or the envelope trimer, has been the basis of renewed and ongoing focus on nAbs. $2 \mathrm{~F} 5$ and $4 \mathrm{E} 10$ are the only $\mathrm{nAbs}$ that bind to linear and accessible viral targets located in the membrane-proximal external region (MPER) of gp41, ELDKWA, and NWFDIT. Several vaccine approaches incorporating MPER epitopes have attempted to mimic 2F5or 4E10-like Abs but have only induced modest responses in vivo. ${ }^{16-19}$ Unfortunately, because of the partial homology of MPER epitopes with autoantigens such as cardiolipin, nAbs of 2F5/4E10-like potency and neutralizing activity are not elicited in the course of natural infection or upon vaccination. ${ }^{20-22}$ Therefore, the identification of novel immunogenic and conserved viral targets that can be incorporated into vaccine models to generate broadly reactive immunity against HIV is still of great interest.

${ }^{1}$ Department of Pathology and Molecular Medicine, Michael G. DeGroote Institute for Infectious Disease Research, McMaster University, Hamilton, Ontario, Canada. Correspondence: KL Rosenthal (rosenthl@mcmaster.ca) or S Jain (jains4@mcmaster.ca) 
Although the role of virus-specific Abs has largely focused on the neutralizing ability of IgG in the past, there has been ample emerging evidence supporting the role of alternate mechanisms of protection by non-nAbs, such as Ab-dependent cellular cytotoxicity ${ }^{23-26}$ and $\mathrm{Ab}$-dependent cell-mediated virus inhibition. ${ }^{27,28}$ In addition to the role of IgG, several studies have also reported the importance of IgA against HIV. IgA has proven to be functional in protecting against HIV infection by direct neutralization, ${ }^{29-34}$ by inhibiting transcytosis of HIV across the mucosa, ${ }^{29,31,35-40}$ by intracellular virus neutralization, ${ }^{41,42}$ and by preventing HIV entry past the epithelial lumen. ${ }^{37}$ Furthermore, virus-specific IgA has been independently identified in the serum and cervicovaginal lavage of exposed uninfected (EU) cohorts of European, African, and Asian origins. ${ }^{30,43-45}$ Thus far, there is no firm evidence of an association or causal relationship between virus-specific IgA and natural resistance to HIV in EU individuals. ${ }^{46}$ However, HIV-reactive IgA from such cohorts has exhibited the ability to neutralize $\mathrm{HIV}^{29,31,32}$ and inhibit syncytia formation. ${ }^{30}$ With particular interest to mucosal protection, cervicovaginal lavage-derived secretory IgA from EU can inhibit virus transcytosis in vitro. ${ }^{38,39}$

Only one epitope has been specifically identified as a target of functional IgA obtained from EU discordant couples, QARILAVERY, which is found within the coiled-coil region of gp $41 .{ }^{30,34}$ In a study conducted by Clerici et al. ${ }^{30}$ epitopespecific IgA was purified from the sera of EU individuals and showed effective virus-neutralization capacity. In addition, serum obtained from mice immunized with the QARILAVERY peptide inhibited syncytia formation. Older studies have also reported immunogenicity of coiled-coil region epitopes when delivered in the peptide form, $, 30,47,48$ and showed that peptidespecific Abs could inhibit syncytia formation ${ }^{30,47,49}$ and neutralize HIV in vitro. ${ }^{50}$ The coiled-coil pocket of gp41 (HIV-1 env $583-599)^{51}$ is indeed a highly conserved region and has been reported as such in studies as early as $1988 .^{52}$ It is a relatively stable structure that has proven to be critical in the host-virus membrane fusion process. ${ }^{53}$ Interestingly, serum samples obtained from chronically infected individuals ${ }^{49,50,54}$ and hosts immunized with gp120/gp $41^{54}$ have also shown cross-reactivity to the coiled-coil region, which proves that it is naturally immunogenic. However, since these early studies, the IgAinducing capacity of the coiled-coil region and assessment of the IgA function against HIV, have not been explored further.

We have previously designed and tested an immunization model that generates chimeric Gag virus-like particles (VLPs) in vivo, with the goal to elicit potent Abs against the MPER. The [Gag + MPER]-VLP constructs were expressed in mice through strategic delivery of heterologous DNA and recombinant adenovirus ( $\mathrm{rAd}$ ) vectors in an optimized prime-boost regimen, which elicited potent systemic and mucosal epitope-specific Abs. ${ }^{16}$ The study also independently showed that the expression of multiple tandem copies of an Ab-inducing epitope within a Gag-VLP could significantly increase epitope-specific IgG and IgA titers compared with a single copy. ${ }^{16}$

In this study, we characterized the immunogenicity of the highly conserved gp4lepitope, QARVLAVERY. Different lengths and slight amino-acid (aa) variations of this coiled-coil epitope have been used in previous studies; ${ }^{30,55,56}$ however, here, we specifically characterized the QARVLAVERY epitope. QARVLAVERY-specific Abs were induced systemically and mucosally by immunizing C57Bl/6 mice with DNA and $\mathrm{rAd}$ vectors that generate chimeric [Gag + QARVLAVERY]-VLPs, using previously optimized regimens. ${ }^{16}$ We assessed the immunogenicity of QARVLAVERY in our model, particularly with regard to IgA induction, and in comparison with the ELDKWA-specific IgA induced in similar head-to-head immunization regimens. Furthermore, the functional capacity of QARVLAVERY-specific IgG and IgA from systemic and mucosal samples has been assessed for their HIV infection inhibition or viral transcytosis-inhibition ability, in vitro.

\section{RESULTS}

\section{QARVLAVERY is a highly conserved epitope}

Figure 1 summarizes the overall sequence homology of the QARVLAVERY epitope (aa 577-586) against all the listed HIV-1 sequences in the Los Alamos HIV immunology database. This first-glance analysis is a preliminary indication of the remarkable conservation of this epitope determined using the QuickAlign tool.

Figure 1a summarizes the percentage of total HIV sequences that have differences of $0,1,2,3$, or $>4$ aa in the alignment results of the input sequence "QARVLAVERY," against 2,230 of the total listed HIV-1 sequences ( $\mathrm{T}_{\text {seq }}$ ). As shown, $44.3 \%$ of all listed viral sequences show $100 \%$ alignment with QARVLAVERY (zero changes in aa sequence), and in fact, $79.4 \%$ of all listed viruses only show a difference of 1 aa $(44.3+35.1 \%)$. Figure $1 \mathbf{b}$ shows similar alignment results for the gp41 ELDKWA epitope (aa 622-667) to compare the relative conservation of both epitopes with all listed sequences. Alignment results for QARVLAVERY illustrated in Figure 1c are specific to individual clades, the most prevalent ones worldwide. The global distribution of HIV-1 clade prevalence in Figure 1d was obtained from the geography search interface of the Los Alamos HIV sequence database. It is noteworthy that $73.6 \%$ of all listed clade B sequences have $100 \%$ homology with the QARVLAVERY epitope as it has the highest global prevalence of $62.4 \%$. Furthermore, the percentage of clade-specific HIV sequences that differ from the QARVLAVERY alignment by only 1 aa, ranges from $52 \%$ (clade C: $48.9+3.1 \%$ ) up to $99.1 \%$ (clade 01_AE: $94.6+4.5 \%$ ), i.e., $>50 \%$ of 7 of the most globally prevalent clades only differ from the QARVLAVERY sequence alignment by 1 aa. These results highlight the remarkable sequence conservation of this coiled-coil epitope, potentially making it an attractive immunogenic target to elicit broadly reactive immune responses against HIV-1. Next, we characterized its effectiveness as an antigen in generating epitope-specific Abs, especially IgA, in comparison with ELDKWA.

\section{QARVLAVERY elicits significantly higher IgA compared with ELDKWA in both systemic and mucosal compartments}

To evaluate the immunogenicity of the QARVLAVERY epitope, DNA and rAd vectors expressing the Gag + QARVLAVERY 


\section{Conservation of epitope sequence across all listed clade sequences $\left(T_{\text {seq }}=2,230\right)$}

a

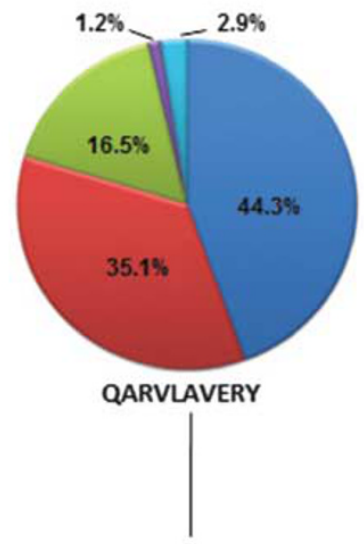

b

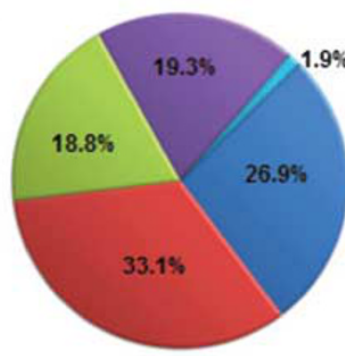

ELDKWA
$0 \Delta-$ aa

$1 \Delta-$ aa

$2 \Delta-$ aa

$3 \Delta-\mathbf{a a}$

$\mathbf{c}^{\prime}$

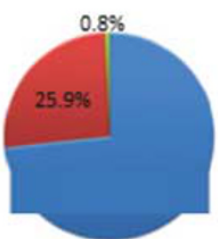

A:

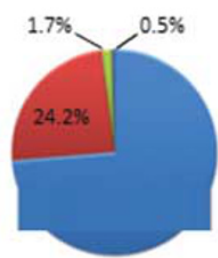

B:

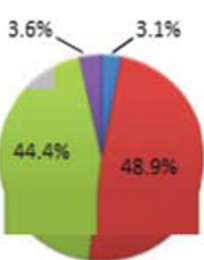

C:

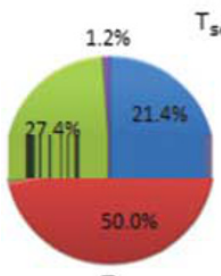

D:

$T_{\text {seq }}=84$

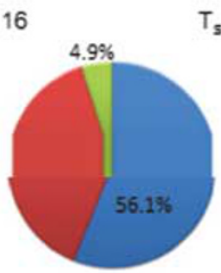

G: $T_{\text {seq }}=697$

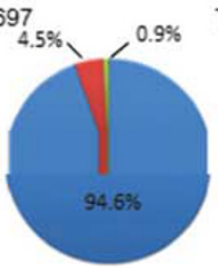

01_AE:

$T_{\text {seq }}=111$

$T_{\text {seq }}=585$

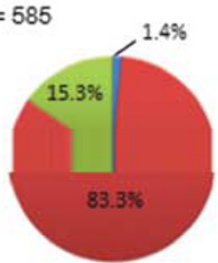

02_AG:

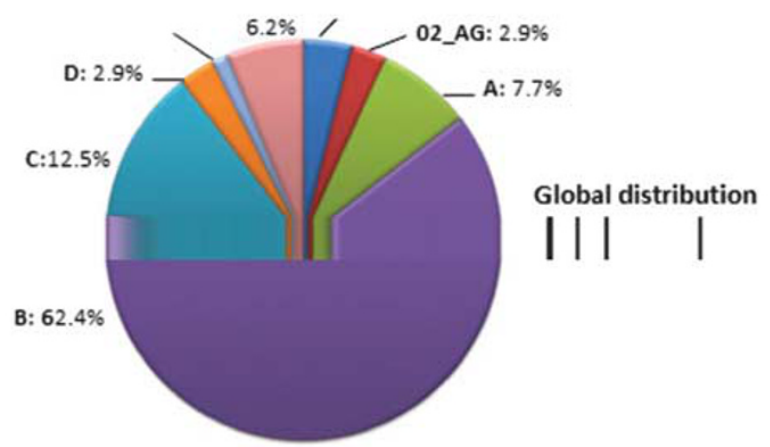

Figure 1 The gp41 epitope QARVLAVERY is highly conserved, as determined by epitope alignment across the listed HIV-1 sequences in the Los Alamos HIV database (dated 10 August 2010). (a) The percentage of sequences that have $0,1,2,3$, or $>4$ point changes in amino-acid sequence ( $\Delta 0$ aa, $\Delta 1$ aa, $\Delta 2$ aa, $\Delta 3$ aa, $>\Delta 4$ aa, respectively) of the epitope QARVLAVERY or (b) ELDKWA. The alignment was performed against all listed HIV sequences $\left(T_{\text {seq }}=2,230\right)$. (c) The percentage of sequences that have $0,1,2,3$, or $>4$ changes in amino acids for the QARVLAVERY epitope alignment, divided by the most prevalent HIV clades. The total number of sequences per clade from which the data were derived is indicated. (d) Global distribution of HIV-1 indicating the relative prevalence of the most widespread clades. Data were obtained from the HIV Los Alamos Geography search interface. HIV, human immunodeficiency virus.

construct were generated for immunization in mice. In a previous study, ${ }^{16}$ we have shown that inserting multiple copies of an epitope, such as ELDKWA, within Gag served as an effective design strategy to generate chimeric VLPs that elicited high titers of ELDKWA-specific Abs. The Gag + QARVLAVERY construct was designed in a similar manner, with three tandem copies of the epitope inserted just before the $\mathrm{C}$ terminus of the gag. The proper formation and release of VLPs from each of the vectors were verified as described before ${ }^{16}$ (data not shown). To contrast the immunogenicity of QARVLAVERY, separate groups of mice were immunized with DNA and rAd vectors expressing [Gag + ELDKWA]-VLPs. QARVLAVERY and ELDKWA 

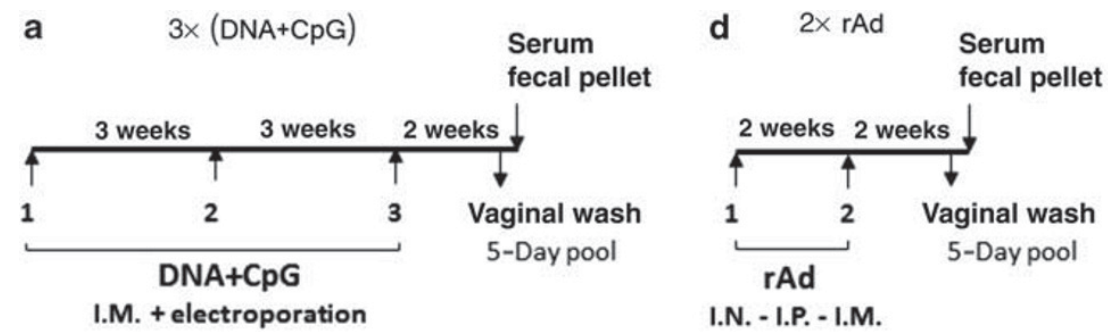

I.N. - I.P. - I.M.

C

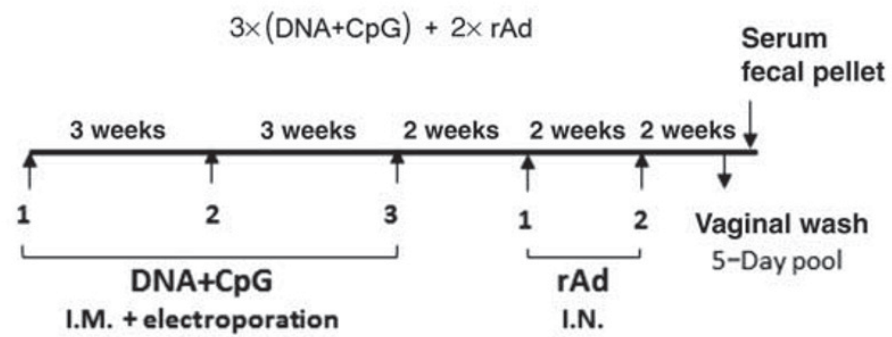

d

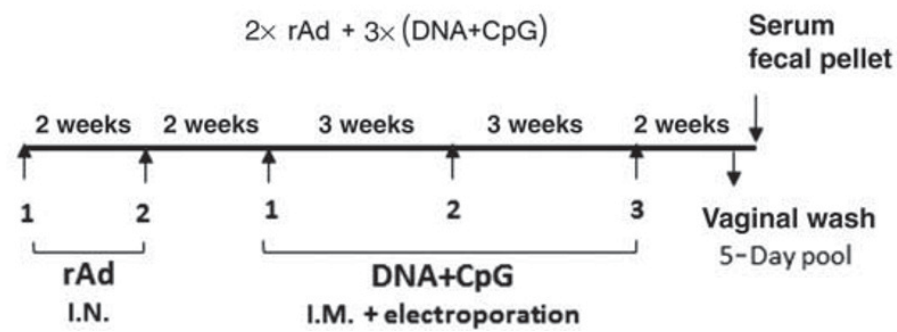

Figure 2 An illustration of the immunization regimens used in subsequent experiments: homologous prime-boost delivery of (a) $3 \times$ DNA I.M. or (b) $2 \times$ rAd, I.N., I.M., or I.P., the heterologous prime-boost delivery of (c) $3 \times(D N A+C p G)$ I.M. $+2 \times$ rAd I.N. or (d) $2 \times$ rAd I.N. $+3 \times(D N A+C p G) ~ I . M . ~ S e r u m$ samples and fecal pellets were collected on day 14 after the last immunization, whereas vaginal wash samples were pooled over 5 consecutive days per mouse ending on day 14, to account for any estrus cycle-dependent Ab shedding over the 5-day hormonal cycle of female mice. rAd, recombinant adenovirus; I.M., intramuscular; I.N., intranasal; or I.P., intraperitoneal.

expressing VLP constructs each had three tandem copies of the respective epitope, inserted at the same site within the gag, delivered by the same vectors and delivery regimen to mice, to be able to directly compare the IgA-inducing ability of both epitopes. Groups of $\mathrm{C} 57 \mathrm{Bl} / 6$ mice were given the optimized prime-boost regimen that elicited the best titers of systemic and mucosal epitope-specific Abs, ${ }^{16} 3 \times(\mathrm{DNA}+\mathrm{CpG})$ administered intramuscularly (I.M.) with immediate local electroporation, followed by $2 \times$ rAd intranasally (I.N.). Figure $2 \mathrm{c}$ illustrates the $3 \times(\mathrm{DNA}+\mathrm{CpG})+2 \times$ rAd immunization scheme. Each set of DNA/rAd constructs expressed either Gag + QARVLAVERY or Gag + ELDKWA.

Results in Figure 3a illustrate an intriguing observation: significantly higher IgA was generated against QARVLAVERY compared with ELDKWA in the serum of immunized C57Bl/6 mice, as well as in mucosal samples: vaginal washes (VWs) and fecal pellets (FPs). As strains of mice have been shown to exhibit unique immunogenic responses to epitopes that may not be reflective of their true immunogenicity, ${ }^{57}$ the same delivery regimen was administered to Balb/c mice to verify that this phenomenon was not solely specific to $\mathrm{C} 57 \mathrm{Bl} / 6$ mice. Once again, significantly higher IgA was elicited against the QARVLAVERY epitope compared with ELDKWA in the serum, VWs, and FPs, of immunized mice (Figure 3b). Epitope-specific Ab titers were determined by peptide-specific enzyme-linked immunosorbent assays (ELISAs). All representative samples (serum, VW, FP) obtained from $\mathrm{C} 57 \mathrm{Bl} / 6$ and $\mathrm{Balb} / \mathrm{c}$ mice that were immunized with mock DNA and rAd vectors did not exhibit any non-specific reactivity against either epitope in the ELISAs compared with baseline (data not shown).

These results show that QARVLAVERY is indeed a potent inducer of IgA systemically and mucosally. In fact, it generated significantly higher epitope-specific IgA than did ELDKWA when delivered by similar constructs administered by the same delivery regimen, in two independent strains of mice.

\section{QARVLAVERY elicits significantly higher IgA than does ELDKWA independent of the vector-delivery regimen}

Recent evidence has suggested that factors such as mucosal delivery of antigens, ${ }^{58}$ use of adjuvants,,${ }^{59,60}$ certain viral antigens, ${ }^{61,62}$ or VLP administration ${ }^{63,64}$ may influence IgA induction and can directly or indirectly modulate $\mathrm{Ab}$ class-switch recombination. Here, we determined whether the significantly higher IgA generated against QARVLAVERY was a property of the epitope alone, independent of such factors in our immunization model. Here, QARVLAVERY vs. ELDKWA IgA titers were compared between groups of mice that were immunized with the following 


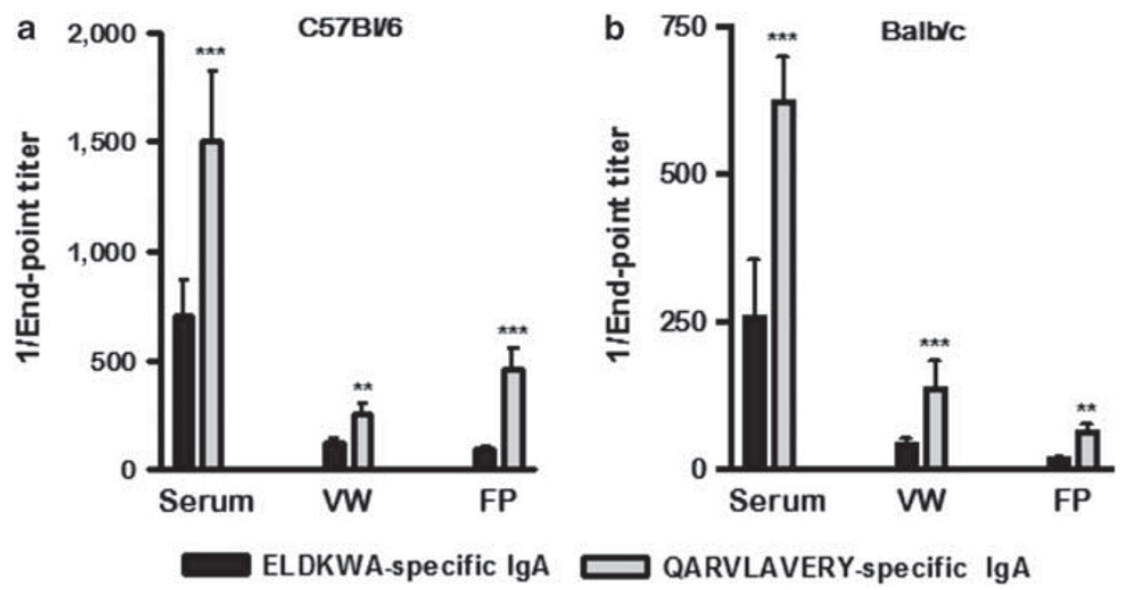

Figure 3 QARVLAVERY induces significantly higher IgA in immunized mice compared with ELDKWA-immunized mice. Epitope-specific IgA titers measured in the serum, vaginal washes (VWs), and fecal pellets (FPs) of mice that were immunized by the following heterologous prime-boost regimen: $(3 \times(\mathrm{DNA}+\mathrm{CpG})+2 \times \mathrm{rAd})$. Separate groups of C57BI/6 mice $(n=7, \mathbf{a})$ or Balb/c mice $(n=5, \mathbf{b})$ were administered DNA and rAd vectors expressing either the Gag + ELDKWA or the Gag + QARVLAVERY constructs, through the prime-boost regimen. Serum samples were obtained at day 14 and VWs were collected over 5 days starting at day 9 , after the last immunization. Results are representative of three independent experiments. ${ }^{\star *} P<0.05,{ }^{* *} P<0.001$ as determined by the Mann-Whitney test. rAd, recombinant adenovirus.

regimens: (i) $3 \times(\mathrm{DNA}+\mathrm{CpG})$ I.M. with electroporation, (ii) $2 \times$ rAd I.N., and (iii) $2 \times$ rAd followed by $3 \times(\mathrm{DNA}+\mathrm{CpG})$. Figure 2 illustrates the different immunization regimens, which were the same, to compare epitope-specific Ab titers head to head.

This served to determine whether QARVLAVERY-specific IgA was uniquely raised against the epitope or whether the use of $\mathrm{CpG}$ as an adjuvant, any viral antigens from rAd or the mucosal vs. systemic priming order, were possible factors influencing the observations made in Figure 3. As the results show, regardless of the immunization regimen, mice immunized with QARVLAVERY induced significantly higher epitope-specific IgA in their serum (Figure 4a) and VWs (Figure 4b) than did mice immunized with ELDKWA. Hence, we can deduce that this characteristic is attributable to the epitope and is independent of $\mathrm{CpG}$, the vectors used or any specific prime-boost regimen.

\section{QARVLAVERY elicits 1:1 ratio of IgG:IgA in the serum of mice administered homologous DNA, rAd, or heterologous DNA+rAd}

In characterizing the $\mathrm{Ab}$ profile generated by QARVLAVERY, another unique attribute of its IgA-inducing capacity was observed. As shown in Figure 5a, the ratio of IgG:IgA titers elicited against the epitope in the serum of immunized mice is $\sim 1: 1$. This was independently observed in all groups of C57Bl/6 mice that received any of the four different immunization regimens. The ratio of IgG:IgA in the VWs of immunized mice was also $\sim 1: 1$, whereas fecal samples exclusively contained epitopespecific IgA (data not shown). Figure 5b shows the IgG:IgA ratio in the serum of mice immunized with the rAd vector twice, intraperitoneally (I.P.) and I.M., to determine whether the $\sim 1: 1$ ratio was independent of the route of immunization. Indeed, the $\sim 1: 1$ ratio was observed in these groups as well. In all of the immunization groups, no significant difference was observed in the serum IgG:IgA titers, which is unusual as systemically induced HIV-specific responses typically consist of higher IgG than IgA. This unique property of QARVLAVERY further adds to its appeal as a highly conserved IgA-inducing epitope.

\section{QARVLAVERY-specific IgA is induced before IgG induction in the serum}

To determine at which point upon immunization the $\sim 1: 1$ IgG:IgA ratio emerges, serum was sampled over days 12,18 , $23,32,37,45,51$, and 60 from mice administered rAdGagQARVLAVERY, two times through two independent routes, I.N. and I.P. The profile of epitope-specific IgA and IgG induced over time is shown in Figure 6a and $\mathbf{b}$. Interestingly, QARVLAVERYspecific IgA emerged earlier than did epitope-specific IgG in the serum of mice delivered rAd I.N. or I.P., even before the booster rAd immunization administered on day 14 . In fact, epitopespecific IgA was significantly higher $(P<0.001)$ than specific IgG at the earlier time points, as indicated in Figure $\mathbf{6 a}$ and $\mathbf{b}$. As these observations were made in groups of mice administered the same vector systemically (I.P.) and mucosally (I.N.), we showed that they are not dependent on the immunization route. This is an unusual observation as antigen-specific IgG responses typically dominate among systemic humoral responses, as shown in Figure $6 \mathrm{c}$ with ELDKWA-specific IgG and IgA responses in mice, which were immunized with rAdGag-ELDKWA, twice, I.N. In fact, these mice elicited significantly higher IgG against ELDKWA at the later time points of days 45, 51, and 60, and no early peptide-specific IgA was detected.

Mice were immunized with a mock rAd vector I.N. and serum samples were obtained on days 12,18 , and 23 to test for possible cross-reactivity of anti-adenovirus IgA with QARVLAVERY in the peptide-specific ELISA. No cross-reactivity against QARVLAVERY was detected; hence, the sensitivity of the assay was confirmed to be specific to the peptide (data not shown). Furthermore, to ensure that QARVLAVERY-specific IgG was not being masked by peptide-specific IgA in the samples because of possible avidity differences between $\mathrm{Ab}$ isotypes, $\operatorname{IgG}$ fractions 

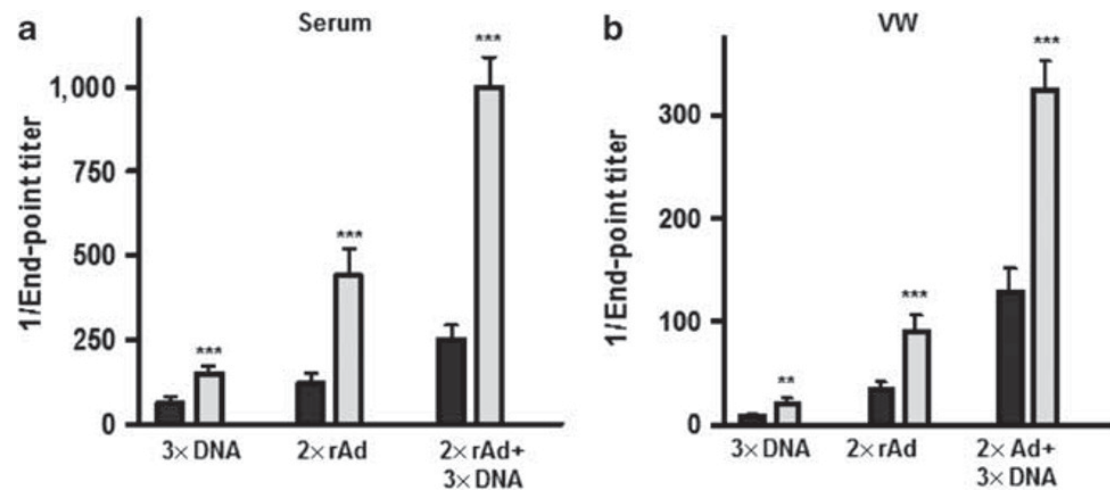

Figure 4 QARVLAVERY induces significantly higher IgA compared with ELDKWA regardless of the vectors or delivery regimen used. Epitopespecific IgA titers in the (a) serum and (b) VWs of C57BI/ 6 mice ( $n=5$ for each group) that were immunized via the following immunization regimes: $(3 \times(D N A+C p G)+2 \times r A d)$ or $(2 \times r A d+3 \times(D N A+C p G))$. For each regimen, mice were immunized with vectors expressing either the Gag + QARVLAVERY construct or the Gag +ELDKWA construct. Serum samples were obtained at day 14 and VWs were collected over 5 days starting at day 9 , after the last immunization. ${ }^{\star \star} P<0.05,{ }^{\star \star \star} P<0.001$. rAd, recombinant adenovirus; $\mathrm{VW}$, vaginal wash.
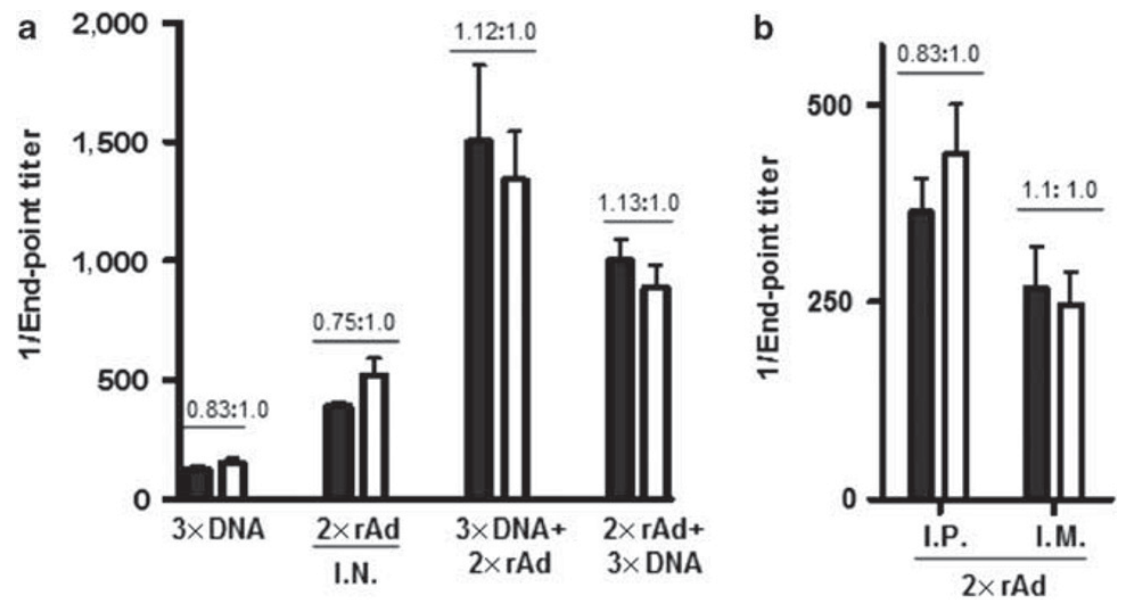

QARVLAVERY-specific IgG

QARVLAVERY-specific IgA

Figure 5 The ratio of serum IgG:IgA raised against QARVLAVERY. (a) Groups of mice ( $n=5$ each) were immunized by the following immunization regimens: $3 \times(D N A+C p G)$ I.M., or $2 \times$ rAd I.N., or $3 \times(D N A+C p G)$, followed by $2 \times$ rAd, or $2 \times$ rAd, followed by $3 \times(D N A+C p G)$, with constructs expressing Gag + QARVLAVERY. (b) QARVLAVERY-specific IgA and IgG in the serum of mice immunized with rAd twice I.P. or I.M. Serum samples were collected at day 14 after the last immunization for all groups. Results are representative of three independent experiments. There was no significant difference between the IgG and IgA titers in any of the groups. rAd, recombinant adenovirus; I.M., intramuscular; I.N., intranasal; or I.P., intraperitoneal.

were purified from serum obtained on days 12,18 , and 23 and re-tested by peptide-specific ELISA. However, purified serum IgG showed no difference in reactivity to QARVLAVERY (data not shown) compared with IgG detected in neat samples at earlier time points as shown in Figure 6a and $\mathbf{b}$. The emergence of early IgA, even before IgG, uniquely against the QARVLAVERY epitope, further highlights the intriguing IgA-inducing capacity of this epitope.

\section{QARVLAVERY-specific IgG is capable of neutralizing X4-tropic IIIB virus but not the R5-tropic ADA viral strain} The relative functional capacity of epitope-specific IgG vs. IgA in the direct neutralization of IIIB and ADA virus strains was assessed using the TZM-bl indicator cell line. Furthermore, the efficiency of QARVLAVERY- vs. ELDKWA-specific Abs in neutralizing IIIB and ADA was also evaluated. Purified IgG- and IgA-enriched fractions were obtained from the serum, VWs, and FPs of mice immunized with either empty vectors or vectors expressing Gag + QARVLAVERY or Gag + ELDKWA. Samples from both immunization groups underwent similar processing that involved elimination of Gag-specific Abs, followed by IgG purification and volume reduction to concentrate both IgG- and IgA-enriched (original sample minus IgG) fractions. Both fractions were equalized for their epitope-specific $\mathrm{Ab}$ content, such that the final working samples contained equal concentrations of QARVLAVERY and ELDKWA specific IgG or IgA, as determined by peptide-specific ELISA. Control serum samples were obtained from mice immunized with mock vectors and were processed in the same manner, whereas control mucosal samples from mock-immunized mice were used neat. The neutralization 

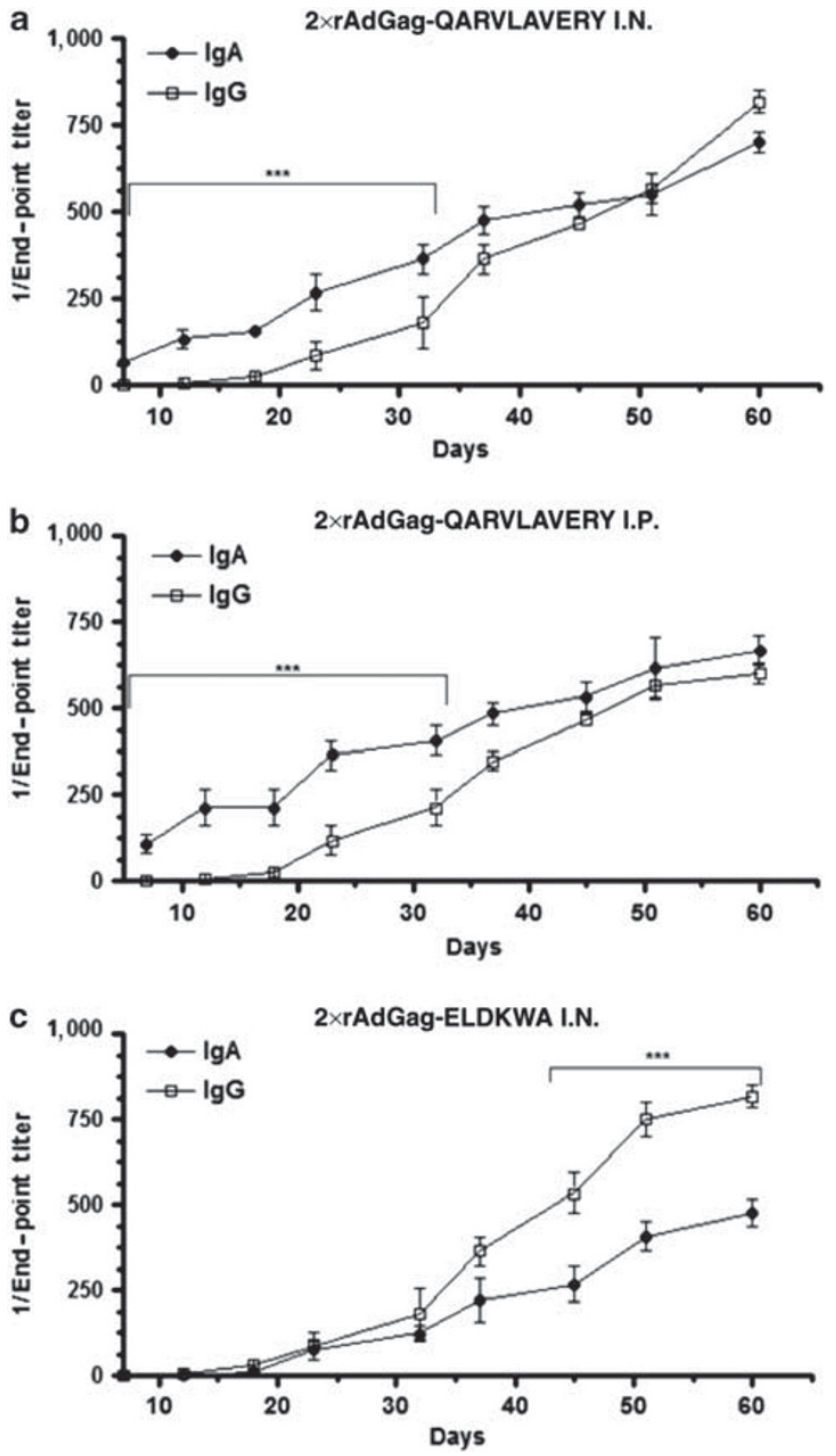

Figure 6 Early detection of QARVLAVERY-specific IgA and IgG in the serum of mice immunized with rAd expressing Gag + QARVLAVERY through the (a) I.N. and (b) I.P. routes, or by rAd expressing Gag +ELDKWA (c) I.N., twice, 2 weeks apart. Serum was obtained starting day 7 and subsequently on days $12,18,23,32,37,45,51$, and 60 . ${ }^{* \star} P<0.001$. Results are representative of at least two independent experiments. rAd, recombinant adenovirus; I.N., intranasal; or I.P., intraperitoneal.

efficiency of $\mathrm{Ab}$ fractions is reflected by the percentage infection inhibition of IIIB or ADA upon pre-incubation with IgG or IgA, relative to direct virus infection in the same assay, in the absence of any inhibitory agent. Positive controls of infection inhibition used were 2F5-IgG, 2F5-IgA, and T20 (Fuzeon, Trimeris, kindly obtained from the NIH AIDS Research and Reference Reagent Program, Germantown, MD), and the concentrations that conferred 90,70 , or $50 \%$ neutralization (IC90/IC70/IC50) of IIIB and ADA were determined in standardizing the assay.

As shown in Figure 7a and $\mathbf{b}$, serum-derived QARVLAVERYspecific IgG and IgA are capable of inhibiting IIIB and ADA virus infection at the indicated Ab dilutions. Although ELDKWAspecific serum IgG exhibits significantly greater neutralizing ability toward the X4-tropic IIIB virus than does QARVLAVERYspecific IgG, it shows no difference in the neutralizing ability against R5-tropic ADA virus. Furthermore, when equal concentrations of IgG and IgA were used under the same assay conditions, as determined by epitope-specific ELISA, IgG against either epitope was significantly more effective in inhibiting virus infection of TZM-bl cells compared with epitope-specific IgA, except for QARVLAVERY-specific IgG against ADA. Mucosally derived $\operatorname{IgG}$ fractions also showed greater neutralizing ability against IIIB compared with IgA (Figure 7c); however, there was no significant difference between IgG and IgA infection inhibition of ADA (Figure 7d). Interestingly, QARVLAVERY-specific IgA from FPs was significantly more effective in neutralizing IIIB than was ELDKWA-specific IgA.

\section{QARVLAVERY-specific IgA effectively inhibits transcytosis of cell-associated IIIB virus}

Here, the ability of epitope-specific Ab fractions to inhibit virus transcytosis upon pre-incubation with IIIB-infected peripheral blood mononuclear cells (PBMCs) was assessed. Ab fractions used were equalized by epitope-specific $\mathrm{Ab}$ content. Infected PBMCs were delivered to the apical compartment of a transwell system, in the presence or absence of purified Abs, over a polarized HEC-1A cell layer. Subsequently, the passage of infectious virus particles to the basolateral compartment was evaluated by the TZM-bl luciferase reporter assay. Basolateral supernatants were concentrated to a final volume of $100 \mu \mathrm{l}$, the entire amount of which was used to quantitatively detect total infectious virus passage through the epithelial layer using the TZM-bl reporter cell line. This method was adopted in lieu of measuring p24 levels, which is not an accurate representation of infectious particles. Percentage reduction in transcytosis efficiency conferred by the Ab samples was determined relative to total transmission of virus from IIIB-infected PBMCs alone, in the absence of inhibitory Abs, under similar conditions.

As seen in Figure 8a, epitope-specific IgA was significantly more efficient in reducing transcytosis efficiency than was epitope-specific IgG (IgA vs. IgG: S-QARV, ${ }^{*} P<0.01$; S-ELD, $\left.{ }^{*} P<0.05\right)$. Furthermore, QARVLAVERY-specific IgA was significantly more effective in inhibiting transcytosis than was ELDKWA-specific IgA (Figure 8b, S-IgA: QARV vs. ELD, $\left.{ }^{*} P<0.01\right)$. This was also observed in FP-derived IgA (FP-IgA: QARV vs. ELD, $\left.{ }^{\star} P<0.05\right)$. Although epitope-specific IgA from VWs was significantly more efficient in reducing virus transcytosis than was specific IgG (Figure 8b, IgA vs. IgG: VW-QARV, ${ }^{* *} P<0.01$; VW-ELD, $\left.{ }^{\star} P<0.05\right)$, there was no significant difference in transcytosis inhibition mediated by QARVLAVERY- vs. ELDKWA-specific IgA from VW samples.

HIV-specific systemic and mucosal IgA, obtained from EU cohorts, have previously been shown to inhibit virus transcytosis in vitro. Here, we compared the ability of purified IgG- and IgA-enriched fractions obtained from Gag + QARVLAVERY- vs. Gag + ELDKWA-immunized mice, to reduce virus transcytosis efficiency upon pre-incubation of IIIB-infected PBMCs with either $\mathrm{Ab}$ fraction. 

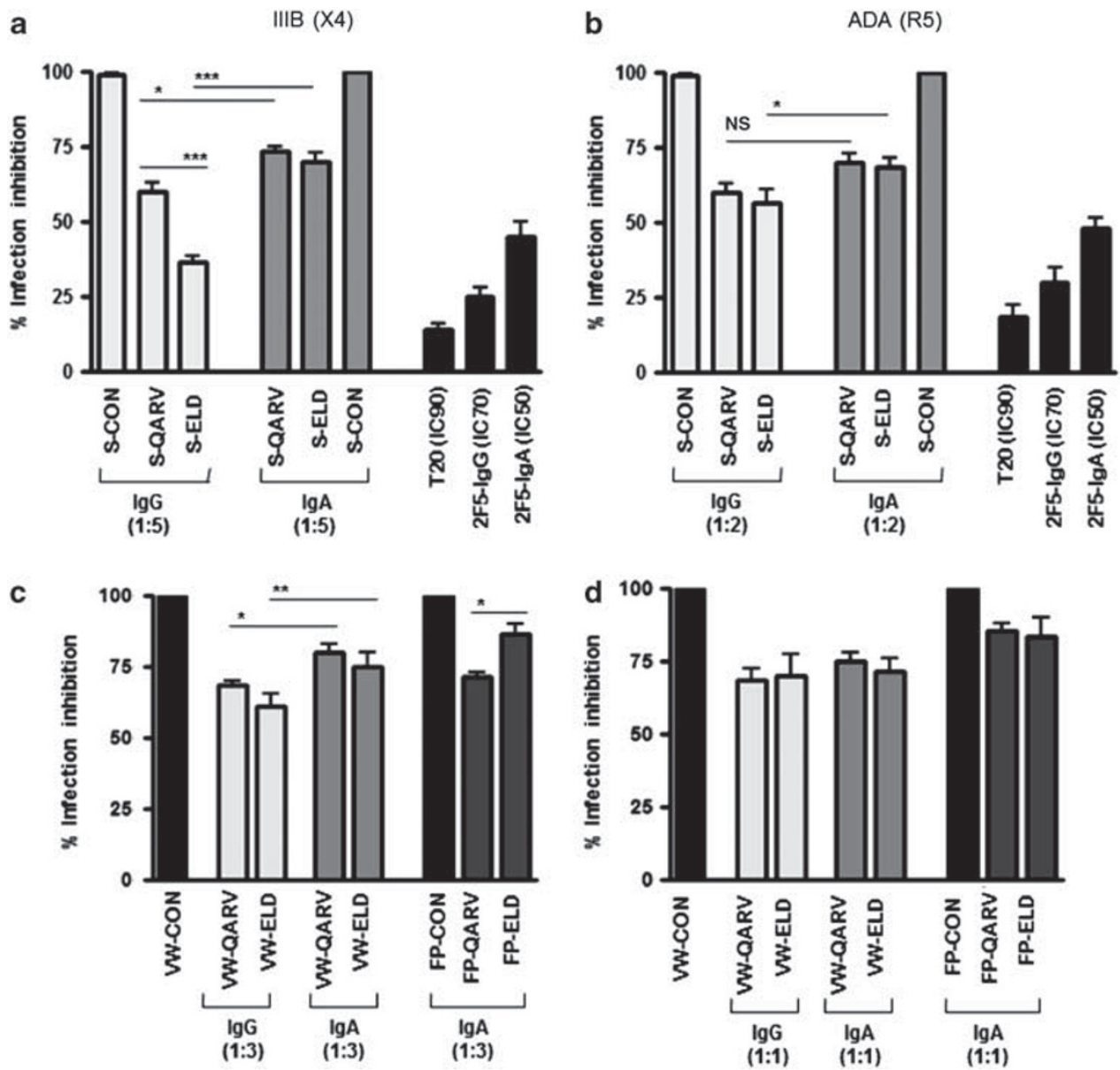

Figure 7 Neutralization efficiency of purified IgG- and IgA-enriched samples obtained from serum (S), vaginal wash (VWs) and fecal pellet (FPs) samples assessed by the TZM-bl reporter against the (a: serum, c: VW, FP) IIIB and (b: serum, d: VW, FP) ADA virus strains. Samples were obtained from control mice $(C O N)$ or mice immunized with the $(3 \times(D N A+C p G)+2 \times r A d)$ regimen, expressing either Gag + QARVLAVERY (QARV) or Gag + ELDKWA (ELD). The aliquots of purified IgG- and IgA-enriched fractions were equalized for their peptide-specific Ab content determined by epitope-specific ELISA. Equivalent dilutions of the IgG and IgA fractions were used, as indicated, for direct comparison between QARVLAVERY and ELDKWA-specific IgG and IgA. Percentage inhibition of infection of TZM-bl cells was determined by the reduction in relative luminescence units (RLUs) upon pre-incubation of virus with mouse IgG and IgA Abs, the 2F5 mAbs or T20 (Fuzeon, Trimeris), relative to direct virus infection of TZM-bl cells alone in the same assay. The average of a minimum of five samples per group is shown. ${ }^{\star \star \star} P<0.001,{ }^{\star \star} P<0.01,{ }^{\star} P<0.05$. Ab, antibody; mAb, monoclonal antibody; NS, not significant.

\section{Infection inhibition and transcytosis inhibition of IIIB by total $\lg G$ and $\lg A$ fractions}

In the previous figures, $\mathrm{Ab}$ fractions used were equalized by peptide-specific content to be able to compare the efficacy of epitope-specific Abs elicited by immunization. Although epitope-specific ELISA used to quantitate the Ab content has been previously optimized for sensitivity and specificity, ${ }^{16}$ Abs of lower avidity or conformational dependence may not bind efficiently to linear epitopes used in the ELISA. Here, we assessed the efficiency of serum and mucosal $\mathrm{Ab}$ fractions that were equalized at the final step according to their total IgG or IgA content, instead of epitope-specific content. Only the raw data are shown, as statistical comparison between IgG and IgA efficacy or between samples obtained from mice immunized with ELDKWA- vs. QARVLAVERY-expressing constructs cannot be made. The assays were performed by the same method, using all appropriate controls as described above.

\section{DISCUSSION}

Despite its expansive global spread, HIV has a surprisingly low natural rate of transmission. In a cohort of discordant heterosexual couples, the reported rate ranged from 0.0001 to $0.0040 .{ }^{65}$ This low rate of transmission is suggestive of some form of natural protective barrier or immune control at the mucosa. IgA is one suggested correlate of mucosal protection against HIV. ${ }^{29}$

In this study, we evaluated the immunogenicity of the highly conserved QARVLAVERY epitope in an optimized prime-boost vaccination model, and assessed the function of QARVLAVERYspecific IgG and IgA elicited in systemic and mucosal compartments. Our collective results highlight an intriguing property of QARVLAVERY: that it is a potent inducer of IgA. This was demonstrated by its ability to consistently generate significantly higher IgA in comparison with ELDKWA, using different immunization regimens and vectors. In addition, it elicited an unusual 1:1 ratio of IgG:IgA, and QARVLAVERYspecific IgA was detected even before IgG in the serum. With 


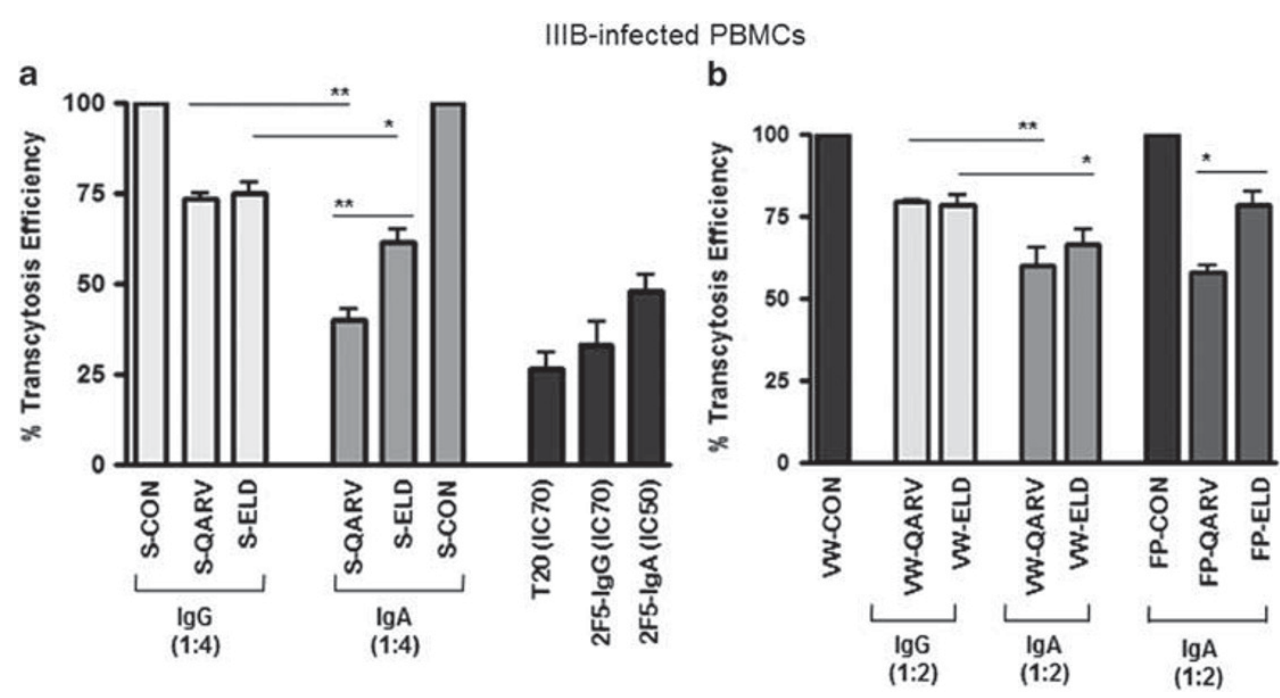

Figure 8 Transcytosis inhibition of purified IgG- and IgA-enriched fractions from the (a) serum (S), (b) VWs, and FPs of control mice (Con) or mice immunized with Gag +QARVLAVERY (QARV) or Gag + ELDKWA (ELD). Final Ab fractions equalized by their epitope-specific IgG and IgA content and appropriate dilutions based on titrations curves were used as indicated (1:4 or 1:2). Transcytosis of virus from IIIB-infected PBMCs across a polarized epithelial layer of HEC-1A cells was measured by detecting passaged infectious virus particles in the basolateral transwell compartment, in a TZM-bl luciferase reporter assay. Percentage reduction in virus passage across the epithelium upon pre-incubation of infected PBMCs with the diluted Ab fractions from immunized mice, mAbs (2F5-IgA, 2F5-IgG) or T20 (Fuzeon, Trimeris), was determined by direct comparison of relative transcytosis efficiency of virus alone in the same manner. The average of a minimum of five samples per group is shown. ${ }^{* \star} P<0.01,{ }^{*} P<0.05$. Ab, antibody; FP, fecal pellet; mAb, monoclonal antibody; PBMC, peripheral blood mononuclear cell; VW, vaginal wash.

particular importance and relevance to inducing mucosal immunity against HIV, QARVLAVERY-specific IgA was found to be functional and effective in inhibiting HIV infection and viral transcytosis across an epithelial barrier in vitro.

Our primary analysis of overall sequence conservation of the QARVLAVERY epitope against all listed HIV-1 sequences in the Los Alamos HIV database reflected the striking conservation of this epitope, particularly among the most prevalent clades worldwide. Earlier studies have also implicated high reactivity of serum from HIV-seropositive individuals against the coiled-coil region of gp41. ${ }^{47,50,54}$ The QARVLAVERY epitope is located at the $\alpha$-helix of the gp41 coiled-coil region, which is involved in the critical cell-fusion process. ${ }^{30}$ Therefore, investigation to identify the critical residues that are involved in $\mathrm{Ab}$ recognition and possible conformational constraints required for proper $\mathrm{Ab}$ function should be pursued to further characterize this epitope, which could be an ideal candidate immunogen to elicit broadly reactive mucosal immunity against HIV.

IgA is known to be the dominant functional isotype at the mucosa; however, contrary to other mucosal sites, female genital tract secretions predominantly consist of IgG rather than IgA. ${ }^{66,67}$ This is attributed to the diffusion of circulatory Abs into genital secretions. Various immunization regimens have attempted to elicit mucosal immunity in simian models of Simian immunodeficiency virus infection but were unable to detect antigen-specific B cells at the genital tract, even though HIVspecific CD8 T-cell induction has been shown. ${ }^{6-71}$ Therefore, as antigen-specific Abs in genital secretions are likely to be derived from systemic circulation, it is intriguing that QARVLAVERY generates unusually high IgA in the serum; in fact, 1:1 IgG:
IgA. Interestingly, the $~ 1: 1$ ratio of QARVLAVERY-specific IgG: IgA that we observed has been reflected by data presented in a previous study (gp41 coil aa 578-592), by an different group. ${ }^{72}$ Although a direct comparison of epitope-specific IgG and IgA against the coiled-coil region was not made, their reported data for Abs directed against the MPER and coiled-coil regions correlate with our findings.

Ab-based vaccine strategies have been heavily dominated with the goal to induce neutralizing IgG against HIV, and there are several ongoing efforts to identify novel neutralizable virus targets. ${ }^{73}$ However, there is ample evidence supporting the role of non-neutralizing HIV Abs in conferring protection as well. ${ }^{23-27}$ A recent immunization study in rhesus macaques has demonstrated that HIV-specific Abs could control infection by Ab-dependent cellular cytotoxicity, Ab-dependent cellmediated virus inhibition, and transcytosis-inhibition mechanisms. ${ }^{74}$ Indeed, there was a strong correlation between viremic control and inhibition of transcytosis by rectal $\mathrm{IgA}$, whereas the $\mathrm{nAb}$ response did not correlate with control of viral load. ${ }^{74}$ Furthermore, unlike IgG, high titers of systemic IgA are not as concerning as it is non-inflammatory by nature and does not activate complement by acting through the inhibitory $\mathrm{F} c \alpha$ receptor. ${ }^{75,76}$ There is ample evidence implicating the importance of "immune quiescence" in maintaining HIV resistance in highly exposed persistently seronegative individuals, ${ }^{77-80}$ and in fact, systemic or mucosal inflammation as a result of immune activation may increase the risk of HIV transmission and pathogenesis. ${ }^{81,82}$ Therefore, an IgA-mediated protective, yet non-inflammatory response is a desirable goal to be achieved by prophylactic mucosal vaccines. 

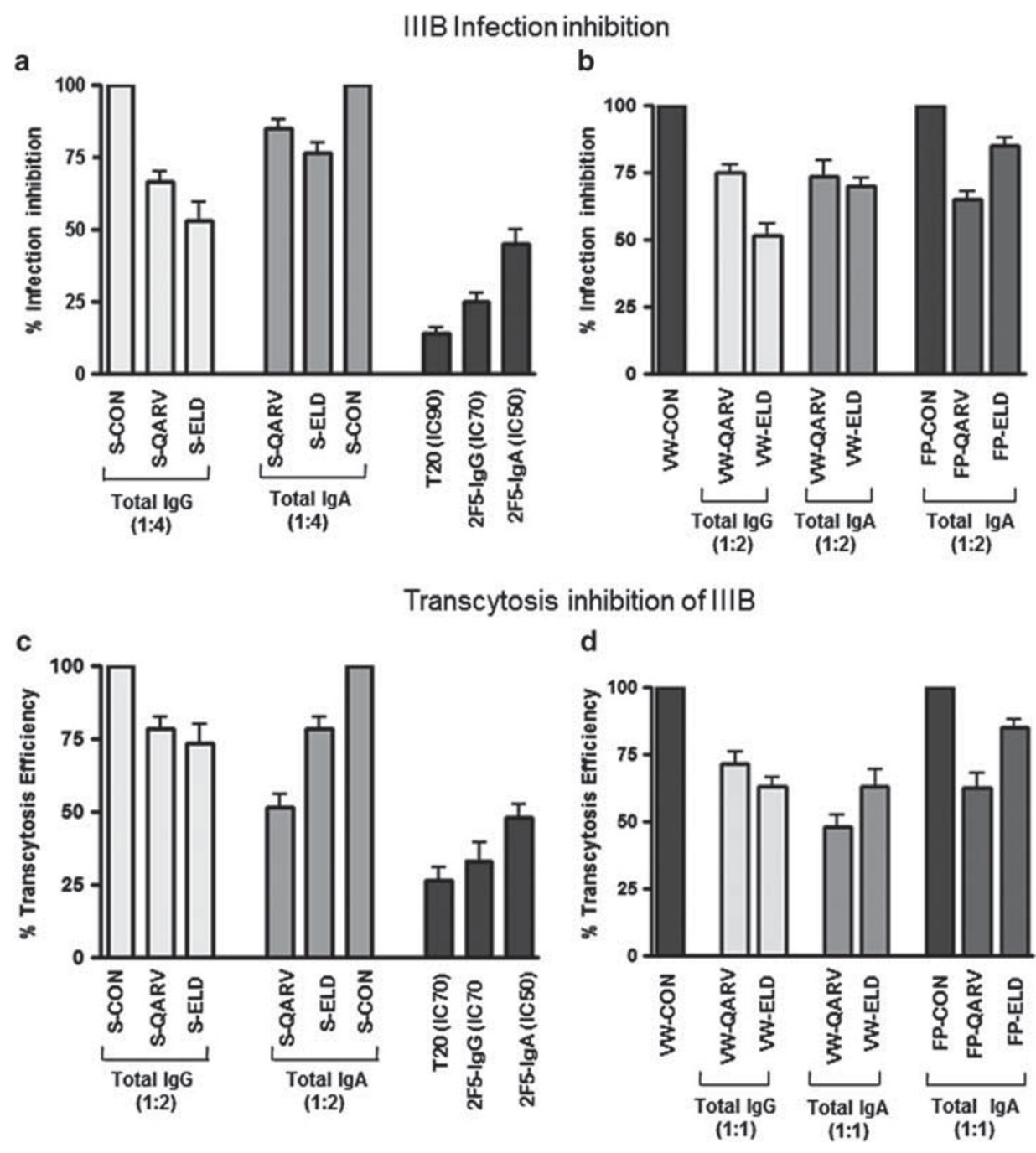

Figure 9 Ab fractions from mice immunized with Gag+QARVLAVERY (QARV) or Gag + ELDKWA (ELD) were enriched, fractionated, and equalized by total IgG or IgA content determined by IgG/IgA ELISA. Serum-derived fractions were assessed for their ability to inhibit direct infection of TZM-bl cells with the IIIB (X4) virus (a) and to inhibit transcytosis of cell-associated IIIB across a HEC-1A cell monolayer in a transwell assay (c), whereas VW and FP samples were assessed in respective assays in (b) and (d). The TZM-bl luciferase assay was used to quantify their direct infection in panel a and $\mathbf{b}$ or to quantify the total infectious virus that traversed into the basolateral supernatant in panels $\mathbf{c}$ and $\mathbf{d}$. The percentage reduction in infection or transcytosis efficiency is shown relative to virus infection or virus passage across the transwell, in the absence of an inhibitory agent, in the same assay. The average of a minimum of four samples per group is shown. ELISA, enzyme-linked immunosorbent assay; FP, fecal pellet; VW, vaginal wash.

Our results illustrate that QARVLAVERY-specific IgG and IgA exhibit modest neutralization of HIV and are capable of inhibiting virus transcytosis in vitro. In particular, QARVLAVERY-specific IgA was significantly more effective at inhibiting IIIB transcytosis than was ELDKWA-specific $\mathrm{IgA}$, with $\mathrm{Ab}$ fractions equalized by epitope-specific $\mathrm{Ab}$ content. Overall, our results show similar trends: systemic IgG was significantly more effective at direct IIIB virus neutralization compared with IgA, whereas IgA was significantly more efficient at inhibiting cell-associated IIIB transcytosis relative to IgG. Mucosally derived IgG and IgA, directed at either epitope, showed no difference in the neutralizing ability against the R5 virus. However, QARVLAVERY-specific IgA from fecal samples was significantly more efficient both in neutralizing IIIB and in inhibiting virus transcytosis, than was
ELDKWA-specific IgA. It is noteworthy, however, that the hepatic pump in rodents is a mode of passage of circulating polymeric IgA into the gastrointestinal tract. ${ }^{83}$ Therefore, IgA measured in the FPs from immunized mice consists of both mucosally produced and systemic IgA.

Rigorous efforts are being made to profile the early dynamics of systemic $\mathrm{Ab}$ induction to better understand the role of $\mathrm{Abs}$ in acute HIV-1 infection. ${ }^{84-86}$ Although overall knowledge is still sparse, it has been shown that anti-gp41 Ab responses, in particular IgM, are among the first to be generated systemically, followed by class switching to IgG and IgA. ${ }^{1,85}$ It has also been reviewed ${ }^{87}$ that the earliest HIV-specific IgA responses in mucosal secretions appear within 3 weeks after infection and are also gp41 specific. So far, the MPER is the only identified target of the early gp41-specific IgA..$^{88}$ Our results indicate 
that IgA was detected against QARVLAVERY within 7 days of immunization. Therefore, it would be intriguing to determine whether early IgA isolated from acutely infected individuals may be reactive to the gp41 QARVLAVERY epitope. Our data show that QARVLAVERY-specific IgA from immunized mice could confer protection against HIV by direct virus neutralization or by transcytosis inhibition. However, the biological implications of these findings for humans are yet to be determined, especially in light of the differences between human IgA subtypes IgA1 and IgA2, and murine IgA. ${ }^{67}$ Isolating QARVLAVERYspecific IgA in natural HIV infection and acute infection cohorts to determine its function in virus neutralization, transcytosis inhibition, or Fc receptor-mediated mechanisms, would provide additional information on the implications of this epitope in vaccine design.

The unusually early systemic IgA generated against QARVLAVERY, within 7 days of primary immunization, is another intriguing observation of our study. IgA was induced in the serum before IgG, uniquely in response to QARVLAVERY and in contrast to ELDKWA, which displayed an expected antigen-specific $\mathrm{Ab}$ profile. Recently, there has been a growing understanding of the role of innate-like B1 cells, which suggests that they may have a greater role than producing low-affinity polyreactive "natural" Abs as first-line defense at the mucosa. ${ }^{89-92} \mathrm{~B} 1$ cells can also respond to antigens and generate Abs independent of T-cell help, ${ }^{93}$ in extrafollicular compartments. ${ }^{89,94,95}$ An influenza study initially showed that B1 and $\mathrm{B} 2$ subsets exhibit distinct, independent, and critical $\mathrm{Ab}$ functions in response to virus infection. ${ }^{96}$ Subsequently, they showed that influenza-reactive Abs of B1 origin were those responsible for direct virus neutralization and clearance. ${ }^{97}$ In addition, $\mathrm{B} 1$ cells have been reported to switch to IgA more promptly than B2 cells in response to antigen. ${ }^{98}$ Given our data, we hypothesize that the early IgA induced against QARVLAVERY may be a result of direct or indirect stimulation of $\mathrm{B} 1$ cells and that the additional priming of B1 cells may be responsible for the unusually high IgA observed against QARVLAVERY.

With respect to mucosal protection, innate mechanisms and local cytokines are among the first in line to defend against pathogens. Type 1 interferons (IFNs), and particularly IFN- $\alpha$, have been associated with antiviral activity against HIV. ${ }^{99-101}$ Interestingly, sequence similarity between the gp 41 coiled-coil region, RILAVERY - YLKD, and two domains of human ${ }^{102,103}$ and murine IFN- $\alpha$ (--LAV--Y) and IFN- $\beta$ (R-----RYLK), within regions that constitute the IFN- $\alpha / \beta$ receptor-binding site has been reported. ${ }^{103}$ IFN- $\alpha$ has been implicated in stimulating class switching to $\operatorname{IgM}, \operatorname{IgG} 2$, and $\operatorname{IgA},{ }^{104}$ and may be required to generate mucosal IgA. ${ }^{105}$ However, there are concerns that immune activation led by innate sensors at the mucosa may result in inflammation and an influx of HIV target cells, thereby enhancing HIV. ${ }^{81,82,106}$ It would be intriguing for future studies to determine whether anti-QARVLAVERY Abs could prevent IFN signaling at the mucosa and have a role in enhancing innate protection, in addition to its function in inhibiting transcytosis at the mucosa.
In this study, we have shown that a highly conserved HIV epitope, QARVLAVERY, located in a critical $\alpha$-helix region of the gp41 coiled-coil, is a potent IgA inducer. The epitope showed two interesting properties in our model, that it elicited 1:1 ratio of IgG:IgA in the serum of immunized mice and that epitope-specific IgA was detected within days, even earlier than IgG. These findings can have important implications for future vaccines seeking to induce mucosal immunity against HIV. Interestingly, QARVLAVERY-specific IgA exhibited modest HIV neutralization capacity and was an effective inhibitor of HIV transcytosis in vitro, especially in comparison with ELDKWA. This makes QARVLAVERY a very attractive target for the induction of mucosally relevant IgA responses in prophylactic approaches against HIV.

\section{METHODS}

Epitope sequence alignment. The QuickAlign tool found under the Los Alamos HIV immunology database (http://www.hiv.lanl.gov/content/immunology) was used to determine the percentage sequence conservation of the QARVLAVERY epitope that had $0,1,2,3$, or $>4$ aa changes from the input sequence, across all listed HIV-1 sequences. The data indicating global distribution of the predominant HIV clades were obtained from the geography search interface under the "HIV Sequence" database (http://www.hiv.lanl.gov/). All data were recorded as of 10 August 2010.

DNA and rAd vector construction. Recombinant DNA and rAd vectors expressing the [Gag + QARVLAVERY] construct were constructed in the manner described previously. ${ }^{16}$ In brief, three tandem copies of the following gp41 sequence [GIKQLQARVLAVERYLKDQQLLG x3] (HIV-1 envelope: $572 \rightarrow 594$ ) were inserted before the stop codon of a HIV-1 clade A gag gene. The nucleotide sequence of the epitope string insert is: 5' $^{\prime}$-(GGCATCAAACAGCTGCAGGCCAGAATCCTGGTGGA ACGGTATCTGAAAGATCAGCAGCTGCTGGGCGGGATTAAACA GCTCCAGGCTAGGGTCCTGGTCGAGAGATACCTGAAGGACCA ACAGCTCCTGGAAGGAATCAAGCAACTGCAGGCCCGGGTGCT CGTGGAAAGGTATCTCAAAGATCAGCAACTGCTCGGC). Proper generation and formation of Gag + QARVLAVERY chimeric VLPs were verified by western blot characterization, as described previously. ${ }^{16}$

Immunizations and sample collection. Female C57Bl/6 mice, 8-10weeks of age, were used in all the experiments, except for Balb/c mice where mentioned (Charles River, Quebec, Canada). DNA constructs were scaled-up as endotoxin-free preparations for safe use in animals. In all, $50 \mu \mathrm{g}$ DNA was co-administered with $50 \mu \mathrm{g}$ CpG (ODN 1826 , 5' -TCCATGACGTTCCTGACGTT, MOBIX, Hamilton, ON, Canada) I.M. in the hind limbs of mice, immediately followed by electroporation, whereas rAd immunizations were administered I.N. at $10^{8}$ p.f.u. $\mathrm{ml}^{-1}$, as described previously. ${ }^{16}$ Repetitive DNA and rAd immunizations were given 3 or 2 weeks apart, respectively. Where mentioned, rAd was also administered I.P. and I.M. at $10^{8}$ p.f.u. $\mathrm{ml}^{-1}$ in a total volume of $30 \mu \mathrm{l}$, diluted in saline. Samples were collected as described previously. ${ }^{16}$ In brief, serum was obtained from retro-orbital bleeds, VWs were collected over 5 days to account for the estru/diestrus shedding differences, and Abs from collected FPs were left to diffuse out into a $0.05 \%$ sodium azide buffer overnight at $4^{\circ} \mathrm{C}$. All samples were stored at $-80^{\circ} \mathrm{C}$ in the long term.

ELISA. Detailed procedures for detecting epitope-specific IgG or IgA by peptide-specific ELISA have been described previously. ${ }^{16}$ In brief, aminoimmobilizer plates (Nunc, Mississauga, ON, Canada) were coated either with the QARVLAVERY peptide (full sequence: KQLQARVLAVERYLK, CPC Scientific, San Jose, CA) or with the ELLELDKWASL epitope, at $5 \mu \mathrm{g} \mathrm{ml}^{-1}$ per well. Plates were subsequently blocked with $5 \%$ bovine 
serum albumin and washed before addition of sample dilutions. After overnight incubation at $4^{\circ} \mathrm{C}$, a secondary biotin-conjugated anti-mouse IgG or IgA Ab was added to be detected by the colorimetric $3,3^{\prime}, 5,5^{\prime}$ tetramethylbenzidine reagent (KPL, Guelph, ON, Canada). The end point of for each test sample was determined as the dilution at which its OD was at least 1.5 times that of the sample representative sample from a naive, unimmunized mouse of the same strain. The protocol for determining total IgG and IgA titers has also been described before. ${ }^{16}$

Ab fractionation. Gag-specific Abs were pulled out of serum, VW, and FP samples obtained from immunized mice before IgG purification and IgA enrichment. This allowed for a more accurate assessment of the epitopespecific $\mathrm{Ab}$ function in neutralization and transcytosis assays by increasing its relative proportion in the samples. The function of epitope-specific Abs could be assessed without saturating the assays with non-functional Abs and with greater accuracy as purification and fractionation significantly reduced the background. Recombinant p24 (Genway, San Diego, CA) was covalently linked to activated cyanogen-bromide beads (Sigma, Oakville, ON, Canada) and subsequently blocked following the manufacturer's recommendations. Overall, $50 \mu \mathrm{g} \mathrm{ml}^{-1}$ of p24 per $10 \mathrm{ml}$ of bead slurry was sufficient for saturation of available p24-binding sites. The p24-conjugated beads were used to capture anti-p24 Abs present in individual Ab samples from immunized mice. Individual serum, VW, or FP samples were diluted 1:3 in a binding buffer, containing $1 \%$ protease inhibitor (Sigma), before addition of the beads to allow for adsorption of p24-specific Abs, over two rounds, once at room temperature for $1 \mathrm{~h}$ followed by an overnight incubation at $4^{\circ} \mathrm{C}$ with fresh beads, in a rotary apparatus. Unbound fractions containing ELDKWA- or QARVLAVERYspecific Abs were collected and the absence of p24 Abs was confirmed by ELISA. The eluates were applied to Protein A beads (Thermo Scientific, Rockford, IL) for IgG purification as per the manufacturer's recommendations, and the remaining non-IgG fraction is referred to as the IgA-enriched fraction. Aliquots were tested for purity of IgG fractionation by ELISA and dot blots. Final purified IgG and enriched IgA fractions were dialyzed against phosphate-buffered saline and concentrated using 5-K Amicon filter units (Millipore, Burlington, $\mathrm{ON}, \mathrm{Canada})$. Two separate sets of $\mathrm{Ab}$ fractions were used in the functional assays: fractions were either normalized by their epitope-specific IgG and IgA content by ELDKWA/QARVLAVERY-specific ELISA or by total IgG and IgA content as determined by a total IgG/IgA ELISA. Serum samples equalized by epitope-specific IgG or IgA concentration at a final average OD of 3.5 and 1:5, 1:4, or 1:2 dilutions of the concentrated stock were used. VW and fecal secretion samples equalized by epitope-specific content at an average OD of 3.0, and neat (1:1), 1:2, or 1:3 dilutions were used in the assays as indicated. Serum samples equalized by total $\mathrm{Ab}$ content were equalized at a final average OD value of 3.5 in a total IgG or IgA ELISA, and 1:4. 1:2, or 1:1 dilutions were used in the assays. The standard peptide-specific ELISA procedure with appropriate controls has been described previously. ${ }^{16}$ Samples were stored with $1 \%$ anti-protease cocktail (Sigma) at $-80^{\circ} \mathrm{C}$ in the long term.

HIV stock preparation. The lab-adapted IIIB virus strain (X4-tropic) was scaled-up in PBMCs after a 3-day activation with $7 \mu \mathrm{g} \mathrm{ml}^{-1}$ phytohemagglutinin (Sigma) and $35 \mathrm{Units}^{-1}$ of recombinant interleukin-2 (R\&D, Burlington, ON, Canada). The ADA virus (R5-tropic) was passaged and scaled-up in adherent macrophages purified from human peripheral blood. ${ }^{107}$ Supernatants of infected cells were collected at various time points and concentrated using $30-\mathrm{K}$ Amicon filter tubes (Millipore).The median tissue culture infectious dose (TCID50) for each final stock was determined using the Reed-Muench method in TZM-bl cells, which was $5.00 \times 10^{3}$ for the IIIB virus and $2.77 \times 10^{4}$ for the ADA stock. The virus transcytosis assay was performed with IIIB-infected PBMCs prepared from PBMCs isolated from a single donor for all experiments. PBMCs were activated with $7 \mu \mathrm{g} \mathrm{ml}^{-1}$ phytohemagglutinin and $35 \mathrm{Units}^{-1}$ interleukin-2 for 3 days at which point cells were supplemented with fresh interleukin- 2 and infected with 300 TCID50 of IIIB, per $10^{6}$ cells, for an additional 5 days before use in the assay. Cell cytotoxicity was monitored and not observed in the preparation of stocks.

Neutralization assays. TZM-bl cells (JC53-BL) cells produce luciferase under tat control upon HIV infection and were used to determine infection using the standard protocol. ${ }^{108}$ In brief, assays were set up in 96-well plates with $5 \times 10^{4} \mathrm{TZM}$-bl cells and $25 \mu \mathrm{g} \mathrm{ml}^{-1}$ diethylaminoethyl-dextran (Sigma) per well, which was determined to be optimal for significant enhancement of infection in our system. Luciferase production was developed by Bright-Glo reagents (Promega, Sunnyvale, CA) following the manufacturer's protocols, and luminescence was read in the Veritas microplate luminometer (Promega). From the infection curves generated for each virus with increasing TCID50, 175 TCID50 of IIIB and 130 TCID50 of ADA per well were determined to be optimal for $>95 \%$ infection of TZM-bl cells. Assay conditions were standardized by incubation with known infection-inhibiting agents, T20 (Fuzeon, Trimeris), 2F5-IgG (NIH AIDS Research and Reference Reagent Program, Germantown, MD), or monomeric 2F5-IgA (Duke Human Vaccine Institute, Durham, NC). The infection dose of the virus was chosen such that RLUs showed at least a $1.5-\log$ reduction in luminescence in the presence of T20 or the 2F5-monoclonal Abs to accurately determine the neutralization effect. The concentration of monoclonal Abs that conferred 90,70 , or $50 \%$ reduction (IC90, IC70, IC50) of luciferase production in TZM-bl cells was also determined. IC90 for T20 (Fuzeon, Trimeris) was $2 \mathrm{ng} \mathrm{ml}^{-1}$ against IIIB and $5 \mathrm{ng} \mathrm{ml}^{-1}$ against ADA. IC70 of 2F5-IgG against IIIB was $30 \mathrm{ng} \mathrm{ml}^{-1}$ and $100 \mathrm{ng} \mathrm{ml}^{-1}$ against ADA. 2F5-IgA only showed $50 \%$ reduction in RLUs; its IC50 was determined to be $45 \mathrm{ng} \mathrm{ml}^{-1}$ against IIIB and $125 \mathrm{ng} \mathrm{ml}^{-1}$ against ADA. Ab titration curves against IIIB were performed; 1:5 dilutions of the serum-derived IgG/IgA and 1:3 dilutions of mucosal $\operatorname{IgG} / \operatorname{IgA}$ were optimal in neutralization and were used in reported data. Titration curves against ADA showed that 1:2 dilutions of serum $\mathrm{IgG} / \mathrm{IgA}$ and neat mucosal samples gave the highest detectable neutralization. Reducing the TCID50 of ADA did not affect the neutralization capacity. Ab samples were incubated with IIIB or ADA for $1 \mathrm{~h}$ at $37^{\circ} \mathrm{C}$, in triplicate, before TZM-bl cell addition. Final neutralization efficiency was determined based on the average RLU reduction in the presence of $A b$ fractions or $\mathrm{T} 20$ or the $2 \mathrm{~F} 5$-monoclonal Abs, relative to average baseline infection, per plate, and is reported as \% infection inhibition.

Transcytosis-inhibition assay. HEC-1A cells (ATCC, Manassas, VA) were grown as tight polarized monolayers in $0.4-\mu \mathrm{m}$ permeable polycarbonate cell culture inserts or transwells for 24-well plates (Nunc, $\mathrm{BD}$, Burlington, ON, Canada) ${ }^{109}$ in $10 \%$ McCoy's media (Invitrogen, Burlington, ON, Canada). Transcytosis-inhibition assay was performed on cells that had reached a minimum trans-epithelial resistance of 330$420 \Omega \times \mathrm{cm}^{2}$ (EVOM, World Precision Instruments, Sarasota, FL) after being in culture for a minimum of 3 days to form a polarized epithelial layer. IIIB-infected PBMCs were added at $7.5 \times 10^{5}$ per well to the apical transwell compartment over polarized HEC-1A cells, and virus passage to the basolateral compartment was measured at 2, 4 , and $8 \mathrm{~h}$. Basolateral supernatants were collected and concentrated in 30-K Amicon microcentrifugation tubes (Millipore) down to $100 \mu \mathrm{l}$. They were analyzed quantitatively for the content of infectious virus particles by testing the entire $100 \mu \mathrm{l}$ against TZM-bl cells in the luciferase reporter assay. The transcytosis period of $4 \mathrm{~h}$ was determined as optimal for detection of virus particles in basolateral supernatants. Transcytosis-inhibition assay conditions were first standardized by titrating T20, 2F5-IgG, and 2F5-IgA against IIIB-infected PBMCs. On the basis of titration curves, a maximum of $70 \%$ reduction in transcytosis was achieved upon incubation of $7.5 \times 10^{5}$ IIIB-infected PBMCs with $5 \mathrm{ng} \mathrm{ml}^{-1} \mathrm{~T} 20$ (Fuzeon, Trimeris) and $65 \mathrm{ng} \mathrm{ml}^{-1}$ of $2 \mathrm{~F} 5$-IgG per well, and $50 \%$ reduction with $100 \mathrm{ng} \mathrm{ml}^{-1}$ $2 \mathrm{~F} 5-\mathrm{IgA}$, for $2 \mathrm{~h}$ at $37^{\circ} \mathrm{C}$ before the addition of infected-PBMCs apically. The effectiveness of mouse-derived $\mathrm{Ab}$ fractions in inhibiting virus transcytosis was determined by the percentage decrease in the average RLU, relative to the average RLU of basolateral supernatants from IIIB-infected PBMCs that were not incubated by any inhibitory agent. Ab titrations from the working aliquots of purified IgG and IgA-enriched fractions 
were performed; 1:4 dilutions of serum-derived IgG and IgA fractions and 1.2 dilutions of mucosal IgG and IgA fractions were determined to be optimal in the reduction of transcytosis.

Statistics. All significance data were obtained using the Mann-Whitney test to directly compare two groups, using the GraphPad Prism 4 software (Graphpad, LaJolla, CA). Significance values are indicated by ${ }^{* *} P<0.001$, ${ }^{*} P<0.01$, and ${ }^{\star} P<0.05$.

\section{ACKNOWLEDGMENTS}

We thank Anna Drannik for assistance with HIV neutralization and transcytosis-inhibition assays. This study was supported in part by the Ontario HIV Treatment Network (OHTN) Studentship Award to Sumiti Jain (2004-2006, 2007-2009) and a Career Scientist Award to Kenneth L Rosenthal. This work was also supported by funds from the Canadian Network for Vaccines and Immunotherapeutics (CANVAC) and the Centers for AIDS Vaccine Development (CAVD).

\section{DISCLOSURE}

The authors declared no conflict of interest.

() 2011 Society for Mucosal Immunology

\section{REFERENCES}

1. Tomaras, G.D. \& Haynes, B.F. HIV-1-specific antibody responses during acute and chronic HIV-1 infection. Curr. Opin. HIV AIDS 4, 373-379 (2009).

2. Moore, P.L. et al. Nature of nonfunctional envelope proteins on the surface of human immunodeficiency virus type 1. J. Virol. 80, 2515-2528 (2006).

3. Moore, P.L. et al. Limited neutralizing antibody specificities drive neutralization escape in early HIV-1 subtype C infection. PLoS Pathog. 5, e1000598 (2009).

4. Rong, R. et al. Escape from autologous neutralizing antibodies in acute/ early subtype $\mathrm{C} \mathrm{HIV-1}$ infection requires multiple pathways. PLOS Pathog. 5, e1000594 (2009).

5. Flynn, N.M., Forthal, D.N., Harro, C.D., Judson, F.N., Mayer, K.H. \& Para, M.F. Placebo-controlled phase 3 trial of a recombinant glycoprotein 120 vaccine to prevent HIV-1 infection. J. Infect. Dis. 191, 654-665 (2005).

6. Lee, D. et al. Breakthrough infections during phase 1 and 2 prime-boost HIV-1 vaccine trials with canarypox vectors (ALVAC) and booster dose of recombinant gp120 or gp160. J. Infect. Dis. 190, 903-907 (2004).

7. Goulder, P.J. et al. Late escape from an immunodominant cytotoxic Tlymphocyte response associated with progression to AIDS. Nat. Med. 3, 212-217 (1997).

8. Allen, T.M. et al. Selection, transmission, and reversion of an antigenprocessing cytotoxic T-lymphocyte escape mutation in human immunodeficiency virus type 1 infection. J. Virol. 78, 7069-7078 (2004).

9. zur Megede, J. et al. A therapeutic SIV DNA vaccine elicits T-cell immune responses, but no sustained control of viremia in SIVmac239-infected rhesus macaques. AIDS Res. Hum. Retroviruses 24, 1103-1116 (2008).

10. Suh, Y.S. et al. Prolonged survival of vaccinated macaques after oral SIVmac239 challenge regardless of viremia control in the chronic phase. Vaccine 26, 6690-6698 (2008).

11. Zwick, M.B. et al. Broadly neutralizing antibodies targeted to the membrane-proximal external region of human immunodeficiency virus type 1 glycoprotein gp41. J. Virol. 75, 10892-10905 (2001).

12. Zwick, M.B. et al. Neutralization synergy of human immunodeficiency virus type 1 primary isolates by cocktails of broadly neutralizing antibodies. J. Virol. 75, 12198-12208 (2001).

13. Zhou, T. et al. Structural analysis of DFG-in and DFG-out dual Src-Abl inhibitors sharing a common vinyl purine template. Chem. Biol. Drug Des. 75, 18-28 (2010).

14. Corti, D. et al. Analysis of memory B cell responses and isolation of novel monoclonal antibodies with neutralizing breadth from HIV-1-infected individuals. PLoS One 5, e8805 (2010).

15. Pancera, M. et al. Crystal structure of PG16 and chimeric dissection with somatically related PG9: structure-function analysis of two quaternaryspecific antibodies that effectively neutralize HIV-1. J. Virol. 84, 8098-8110 (2010).
16. Jain, S., Patrick, A.J. \& Rosenthal, K.L. Multiple tandem copies of conserved gp41 epitopes incorporated in gag virus-like particles elicit systemic and mucosal antibodies in an optimized heterologous vector delivery regimen. Vaccine $\mathbf{2 8 , 7 0 7 0 - 7 0 8 0 ~ ( 2 0 1 0 ) . ~}$

17. Ura, T. et al. Designed recombinant adenovirus type 5 vector induced envelope-specific CD8(+) cytotoxic T lymphocytes and cross-reactive neutralizing antibodies against human immunodeficiency virus type 1. J. Gene Med. 11, 139-149 (2009).

18. Lapelosa, M., Arnold, G.F., Gallicchio, E., Arnold, E. \& Levy, R.M. Antigenic characteristics of rhinovirus chimeras designed in silico for enhanced presentation of HIV-1 gp41 epitopes [corrected]. J. Mol. Biol. 397, 752-766 (2010).

19. Liao, M., Lu, Y., Xiao, Y., Dierich, M.P. \& Chen, Y. Induction of high level of specific antibody response to the neutralizing epitope ELDKWA on HIV-1 gp41 by peptide-vaccine. Peptides 21, 463-468 (2000).

20. Haynes, B.F. et al. Cardiolipin polyspecific autoreactivity in two broadly neutralizing HIV-1 antibodies. Science 308, 1906-1908 (2005).

21. Matyas, G.R., Beck, Z., Karasavvas, N. \& Alving, C.R. Lipid binding properties of 4E10, 2F5, and WR304 monoclonal antibodies that neutralize HIV-1. Biochim. Biophys. Acta. 1788, 660-665 (2009).

22. Verkoczy, L. et al. Autoreactivity in an HIV-1 broadly reactive neutralizing antibody variable region heavy chain induces immunologic tolerance. Proc. Natl Acad. Sci. USA 107, 181-186 (2010).

23. Tyler, D.S. et al. Identification of sites within gp41 that serve as targets for antibody-dependent cellular cytotoxicity by using human monoclonal antibodies. J. Immunol. 145, 3276-3282 (1990).

24. Lambotte, O. et al. Heterogeneous neutralizing antibody and antibodydependent cell cytotoxicity responses in HIV-1 elite controllers. AIDS 23, 897-906 (2009)

25. Gomez-Roman, V.R. et al. Vaccine-elicited antibodies mediate antibodydependent cellular cytotoxicity correlated with significantly reduced acute viremia in rhesus macaques challenged with SIVmac251. J. Immunol. 174, 2185-2189 (2005).

26. Hessell, A.J. et al. Fc receptor but not complement binding is important in antibody protection against HIV. Nature 449, 101-104 (2007).

27. Forthal, D.N. \& Moog, C. Fc receptor-mediated antiviral antibodies. Curr. Opin. HIV AIDS 4, 388-393 (2009)

28. Duval, M., Posner, M.R. \& Cavacini, L.A. A bispecific antibody composed of a nonneutralizing antibody to the gp41 immunodominant region and an anti-CD89 antibody directs broad human immunodeficiency virus destruction by neutrophils. J. Virol. 82, 4671-4674 (2008).

29. Broliden, K. et al. Functional HIV-1 specific IgA antibodies in HIV-1 exposed, persistently lgG seronegative female sex workers. Immunol. Lett. 79, 29-36 (2001).

30. Clerici, M. et al. Serum IgA of HIV-exposed uninfected individuals inhibit HIV through recognition of a region within the alpha-helix of gp41. AIDS 16, 1731-1741 (2002).

31. Devito, C. et al. Cross-clade HIV-1-specific neutralizing IgA in mucosal and systemic compartments of HIV-1-exposed, persistently seronegative subjects. J. Acquir. Immune Defic. Syndr. 30, 413-420 (2002).

32. Devito, C. et al. Mucosal and plasma IgA from HIV-exposed seronegative individuals neutralize a primary HIV-1 isolate. AIDS 14, 1917-1920 (2000).

33. Mazzoli, S. et al. Human immunodeficiency virus (HIV)-specific IgA and HIV neutralizing activity in the serum of exposed seronegative partners of HIV-seropositive persons. J. Infect. Dis. 180, 871-875 (1999).

34. Pastori, C. et al. HIV neutralizing lgA in exposed seronegative subjects recognise an epitope within the gp41 coiled-coil pocket. J. Biol. Regul. Homeost. Agents 14, 15-21 (2000)

35. Devito, C. et al. Mucosal and plasma IgA from HIV-1-exposed uninfected individuals inhibit HIV-1 transcytosis across human epithelial cells. J. Immunol. 165, 5170-5176 (2000).

36. Tudor, D. et al. HIV-1 gp41-specific monoclonal mucosal IgAs derived from highly exposed but IgG-seronegative individuals block HIV-1 epithelial transcytosis and neutralize CD4(+) cell infection: an IgA gene and functional analysis. Mucosal Immunol. 2, 412-426 (2009).

37. Wright, A., Lamm, M.E. \& Huang, Y.T. Excretion of human immunodeficiency virus type 1 through polarized epithelium by immunoglobulin A. J. Virol. 82, 11526-11535 (2008).

38. Hocini, H. et al. High-level ability of secretory IgA to block HIV type 1 transcytosis: contrasting secretory IgA and lgG responses to glycoprotein 160. AIDS Res. Hum. Retroviruses 13, 1179-1185 (1997). 
39. Belec, L. et al. Cervicovaginal secretory antibodies to human immunodeficiency virus type $1(\mathrm{HIV}-1)$ that block viral transcytosis through tight epithelial barriers in highly exposed HIV-1-seronegative African women. J. Infect Dis. 184, 1412-1422 (2001).

40. Alfsen, A., Iniguez, P., Bouguyon, E. \& Bomsel, M. Secretory IgA specific for a conserved epitope on gp41 envelope glycoprotein inhibits epithelial transcytosis of HIV-1. J. Immunol. 166, 6257-6265 (2001).

41. Bomsel, M. et al. Intracellular neutralization of HIV transcytosis across tight epithelial barriers by anti-HIV envelope protein dlgA or lgM. Immunity 9, 277-287 (1998).

42. Huang, Y.T., Wright, A., Gao, X., Kulick, L., Yan, H. \& Lamm, M.E. Intraepithelial cell neutralization of HIV-1 replication by IgA. J. Immunol. 174, 4828-4835 (2005).

43. Nguyen, M. et al. HIV-specific antibodies but not t-cell responses are associated with protection in seronegative partners of HIV-1-infected individuals in Cambodia. J. Acquir. Immune Defic. Syndr. 42, 412-419 (2006).

44. Lopalco, L. et al. Predictive value of anti-cell and anti-human immunodeficiency virus (HIV) humoral responses in HIV-1-exposed seronegative cohorts of European and Asian origin. J. Gen. Virol. 86, 339-348 (2005).

45. Kaul, R. et al. HIV-1-specific mucosal lgA in a cohort of HIV-1-resistant Kenyan sex workers. AIDS 13, 23-29 (1999).

46. Horton, R.E. et al. Cervical HIV-specific IgA in a population of commercial sex workers correlates with repeated exposure but not resistance to HIV. AIDS Res. Hum. Retroviruses 25, 83-92 (2009).

47. Ebersold, A. et al. Human and murine monoclonal antibodies directed against a conserved sequence from gp41 (aa583-599) of human immunodeficiency virus type 1. Res. Virol. 143, 179-191 (1992).

48. Klasse, P.J., Pipkorn, R. \& Blomberg, J. A cluster of continuous antigenic structures in the transmembrane protein of HIV-1: individual patterns of reactivity in human sera. Mol. Immunol. 28, 613-622 (1991).

49. Vanini, S., Longhi, R., Lazzarin, A., Vigo, E., Siccardi, A.G. \& Viale, G. Discrete regions of HIV-1 gp41 defined by syncytia-inhibiting affinitypurified human antibodies. AIDS 7, 167-174 (1993).

50. Neurath, A.R., Strick, N. \& Lee, E.S. B cell epitope mapping of human immunodeficiency virus envelope glycoproteins with long (19- to 36-residue) synthetic peptides. J. Gen. Virol. 71 (Pt 1), 85-95 (1990).

51. Cai, L., Balogh, E. \& Gochin, M. Stable extended human immunodeficiency virus type $1 \mathrm{gp} 41$ coiled coil as an effective target in an assay for high-affinity fusion inhibitors. Antimicrob. Agents Chemother. 53, 2444-2449 (2009).

52. Klasse, P.J., Pipkorn, R. \& Blomberg, J. Presence of antibodies to a putatively immunosuppressive part of human immunodeficiency virus (HIV) envelope glycoprotein gp41 is strongly associated with health among HIV-positive subjects. Proc. Natl Acad. Sci. USA 85, 5225-5229 (1988).

53. Wexler-Cohen, Y., Johnson, B.T., Puri, A., Blumenthal, R. \& Shai, Y. Structurally altered peptides reveal an important role for $\mathrm{N}$-terminal heptad repeat binding and stability in the inhibitory action of HIV-1 peptide DP178. J. Biol. Chem. 281, 9005-9010 (2006).

54. Goudsmit, J. Immunodominant B-cell epitopes of the HIV-1 envelope recognized by infected and immunized hosts. AIDS 2 (Suppl 1), S41S45 (1988).

55. Klasse, J., Pipkorn, R., Blomberg, J., Han, K.H., Hilton, B. \& Ferretti, J.A. Three-dimensional structure and antigenicity of transmembrane-protein peptides of the human immunodeficiency virus type 1. Effects of a neutralization-escape substitution. FEBS Lett. 323, 68-72 (1993).

56. Schulz, T.F., Jameson, B.A., Lopalco, L., Siccardi, A.G., Weiss, R.A. \& Moore, J.P. Conserved structural features in the interaction between retroviral surface and transmembrane glycoproteins? AIDS Res. Hum. Retroviruses 8, 1571-1580 (1992).

57. Almond, N.M., Worms, M.J., Harnett, W. \& Parkhouse, R.M. Variation in class-specific humoral immune responses of different mouse strains to microfilariae of Dipetalonema viteae. Parasitology 95 (Pt 3), 559-568 (1987).

58. Graham, B.S. et al. Mucosal delivery of human papillomavirus pseudovirus-encapsidated plasmids improves the potency of DNA vaccination. Mucosal Immunol. 3, 475-486 (2010).

59. Lu, B. et al. Effect of mucosal and systemic immunization with virus-like particles of severe acute respiratory syndrome coronavirus in mice. Immunology 130, 254-261 (2010).
60. Avramidis, N., Victoratos, P., Yiangou, M. \& Hadjipetrou-Kourounakis, L. Adjuvant regulation of cytokine profile and antibody isotype of immune responses to Mycoplasma agalactiae in mice. Vet. Microbiol. $\mathbf{8 8}$, 325-338 (2002).

61. Bessa, J. et al. Alveolar macrophages and lung dendritic cells sense RNA and drive mucosal IgA responses. J. Immunol. 183, 3788-3799 (2009).

62. He, B. et al. HIV-1 envelope triggers polyclonal Ig class switch recombination through a $\mathrm{CD} 40$-independent mechanism involving BAFF and C-type lectin receptors. J. Immunol. 176, 3931-3941 (2006).

63. Zhang, S., Cubas, R., Li, M., Chen, C. \& Yao, Q. Virus-like particle vaccine activates conventional $\mathrm{B} 2$ cells and promotes $\mathrm{B}$ cell differentiation to IgG2a producing plasma cells. Mol. Immunol. 46, 1988-2001 (2009).

64. Yang, R. et al. B lymphocyte activation by human papillomavirus-like particles directly induces Ig class switch recombination via TLR4MyD88. J. Immunol. 174, 7912-7919 (2005).

65. Gray, R.H. et al. Probability of HIV-1 transmission per coital act in monogamous, heterosexual, HIV-1-discordant couples in Rakai, Uganda. Lancet 357, 1149-1153 (2001).

66. Mestecky, J. et al. Paucity of antigen-specific lgA responses in sera and external secretions of HIV-type 1-infected individuals. AIDS Res. Hum. Retroviruses 20, 972-988 (2004).

67. Mestecky, J., Moldoveanu, Z., Smith, P.D., Hel, Z. \& Alexander, R.C. Mucosal immunology of the genital and gastrointestinal tracts and HIV-1 infection. J. Reprod. Immunol. 83, 196-200 (2009).

68. Goodsell, A. et al. Beta7-integrin-independent enhancement of mucosal and systemic anti-HIV antibody responses following combined mucosal and systemic gene delivery. Immunology 123, 378-389 (2008).

69. Lehner, T. et al. Targeted lymph node immunization with simian immunodeficiency virus p27 antigen to elicit genital, rectal, and urinary immune responses in nonhuman primates. J. Immunol. 153, 1858-1868 (1994).

70. Lehner, T. et al. Mucosal model of genital immunization in male rhesus macaques with a recombinant simian immunodeficiency virus p27 antigen. J. Virol. 68, 1624-1632 (1994).

71. Stevceva, L. et al. Cervicovaginal lamina propria lymphocytes: phenotypic characterization and their importance in cytotoxic Tlymphocyte responses to simian immunodeficiency virus SIVmac251. J. Virol. 76, 9-18 (2002).

72. Devito, C. et al. Intranasal HIV-1-gp160-DNA/gp41 peptide prime-boost immunization regimen in mice results in long-term HIV-1 neutralizing humoral mucosal and systemic immunity. J. Immunol. 173, 7078-7089 (2004).

73. Walker, L.M. et al. Broad and potent neutralizing antibodies from an African donor reveal a new HIV-1 vaccine target. Science 326, 285-289 (2009).

74. Xiao, P. et al. Multiple vaccine-elicited nonneutralizing antienvelope antibody activities contribute to protective efficacy by reducing both acute and chronic viremia following simian/human immunodeficiency virus SHIV89.6P challenge in rhesus macaques. J. Virol. 84, 7161-7173 (2010).

75. Russell, M.W., Sibley, D.A., Nikolova, E.B., Tomana, M. \& Mestecky, J. IgA antibody as a non-inflammatory regulator of immunity. Biochem. Soc. Trans. 25, 466-470 (1997).

76. Pasquier, B. et al. Identification of FcalphaRI as an inhibitory receptor that controls inflammation: dual role of FCRgamma ITAM. Immunity 22, 31-42 (2005).

77. Lester, R.T. et al. HIV-1 RNA dysregulates the natural TLR response to subclinical endotoxemia in Kenyan female sex-workers. PLoS One 4, e5644 (2009).

78. Lester, R.T. et al. Toll-like receptor expression and responsiveness are increased in viraemic HIV-1 infection. AIDS 22, 685-694 (2008).

79. Card, C.M., McLaren, P.J., Wachihi, C., Kimani, J., Plummer, F.A. \& Fowke, K.R. Decreased immune activation in resistance to HIV-1 infection is associated with an elevated frequency of CD4(+)CD25(+) FOXP3(+) regulatory T cells. J. Infect. Dis. 199, 1318-1322 (2009).

80. Horton, R.E. et al. A comparative analysis of gene expression patterns and cell phenotypes between cervical and peripheral blood mononuclear cells. PLoS One 4, e8293 (2009).

81. Lawn, S.D., Butera, S.T. \& Folks, T.M. Contribution of immune activation to the pathogenesis and transmission of human immunodeficiency virus 
type 1 infection. Clin. Microbiol. Rev. 14, 753-777, table of contents (2001).

82. Brenchley, J.M. \& Douek, D.C. The mucosal barrier and immune activation in HIV pathogenesis. Curr. Opin. HIV AIDS 3, 356-361 (2008).

83. Brown, W.R. \& Kloppel, T.M. The liver and IgA: immunological, cell biological and clinical implications. Hepatology 9, 763-784 (1989).

84. Li, Y. et al. Analysis of neutralization specificities in polyclonal sera derived from human immunodeficiency virus type 1 -infected individuals. J. Virol. 83, 1045-1059 (2009).

85. Tomaras, G.D. et al. Initial B-cell responses to transmitted human immunodeficiency virus type 1: virion-binding immunoglobulin M (IgM) and IgG antibodies followed by plasma anti-gp41 antibodies with ineffective control of initial viremia. J. Virol. 82, 12449-12463 (2008).

86. Gray, E.S. et al. Antibody specificities associated with neutralization breadth in plasma from human immunodeficiency virus type 1 subtype C-infected blood donors. J. Virol. 83, 8925-8937 (2009).

87. McMichael, A.J., Borrow, P., Tomaras, G.D., Goonetilleke, N. \& Haynes, B.F. The immune response during acute HIV-1 infection: clues for vaccine development. Nat. Rev. Immunol. 10, 11-23 (2010).

88. Alam, S.M. et al. Human immunodeficiency virus type $1 \mathrm{gp} 41$ antibodies that mask membrane proximal region epitopes: antibody binding kinetics, induction, and potential for regulation in acute infection. J. Virol. 82, 115-125 (2008).

89. Macpherson, A.J., Gatto, D., Sainsbury, E., Harriman, G.R., Hengartner, H. \& Zinkernagel, R.M. A primitive T cell-independent mechanism of intestinal mucosal IgA responses to commensal bacteria. Science $\mathbf{2 8 8}$, 2222-2226 (2000).

90. Alugupalli, K.R., Leong, J.M., Woodland, R.T., Muramatsu, M., Honjo, T. \& Gerstein, R.M. B1b lymphocytes confer T cell-independent longlasting immunity. Immunity 21, 379-390 (2004).

91. Hsu, M.C., Toellner, K.M., Vinuesa, C.G. \& Maclennan, I.C. B cell clones that sustain long-term plasmablast growth in T-independent extrafollicular antibody responses. Proc. Natl Acad. Sci. USA 103, 5905-5910 (2006).

92. Whitmore, A.C., Neely, H.R., Diz, R. \& Flood, P.M. Rapid induction of splenic and peritoneal $\mathrm{B}-1 \mathrm{a}$ cells in adult mice by thymus-independent type-2 antigen. J. Immunol. 173, 5406-5414 (2004).

93. Martin, F., Oliver, A.M. \& Kearney, J.F. Marginal zone and B1 B cells unite in the early response against T-independent blood-borne particulate antigens. Immunity 14, 617-629 (2001).

94. Martin, F. \& Kearney, J.F. B-cell subsets and the mature preimmune repertoire. Marginal zone and B1 B cells as part of a "natural immune memory". Immunol. Rev. 175, 70-79 (2000).
95. Stoel, M. et al. Restricted IgA repertoire in both B-1 and B-2 cell-derived gut plasmablasts. J. Immunol. 174, 1046-1054 (2005).

96. Baumgarth, N., Herman, O.C., Jager, G.C., Brown, L.E., Herzenberg, L.A. \& Chen, J. B-1 and B-2 cell-derived immunoglobulin M antibodies are nonredundant components of the protective response to influenza virus infection. J. Exp. Med. 192, 271-280 (2000).

97. Choi, Y.S. \& Baumgarth, N. Dual role for B-1a cells in immunity to influenza virus infection. J. Exp. Med. 205, 3053-3064 (2008).

98. Kaminski, D.A. \& Stavnezer, J. Enhanced lgA class switching in marginal zone and B1 B cells relative to follicular/B2 B cells. J. Immunol. 177, 6025-6029 (2006).

99. Kamga, I. et al. Type I interferon production is profoundly and transiently impaired in primary HIV-1 infection. J. Infect. Dis. 192, 303-310 (2005).

100. Hosmalin, A. \& Lebon, P. Type I interferon production in HIV-infected patients. J. Leukoc. Biol. 80, 984-993 (2006).

101. Poli, G., Orenstein, J.M., Kinter, A., Folks, T.M. \& Fauci, A.S. Interferonalpha but not AZT suppresses HIV expression in chronically infected cell lines. Science 244, 575-577 (1989).

102. Chen, Y.H. \& Dierich, M.P. A common epitope on gp41, IFN-alpha and IFN-beta induces protective activity. Immunol. Today 19, 586-587 (1998).

103. Chen, Y.H., Xiao, Y. \& Dierich, M.P. HIV-1 gp41 and type I interferon: sequence homology and biological as well as clinical implications. Immunol. Res. 22, 61-66 (2000).

104. Estes, D.M., Tuo, W., Brown, W.C. \& Goin, J. Effects of type I/type II interferons and transforming growth factor-beta on B-cell differentiation and proliferation. Definition of costimulation and cytokine requirements for immunoglobulin synthesis and expression. Immunology 95, 604-611 (1998).

105. Thompson, J.M., Whitmore, A.C., Staats, H.F. \& Johnston, R. The contribution of type I interferon signaling to immunity induced by alphavirus replicon vaccines. Vaccine $26,4998-5003$ (2008).

106. Chang, J.J. \& Altfeld, M. Innate immune activation in primary HIV-1 infection. J. Infect. Dis. 202 (Suppl 2), S297-S301 (2010).

107. Platt, E.J., Wehrly, K., Kuhmann, S.E., Chesebro, B. \& Kabat, D. Effects of CCR5 and CD4 cell surface concentrations on infections by macrophagetropic isolates of human immunodeficiency virus type 1. J. Virol. 72, 2855-2864 (1998).

108. Montefiori, D.C. Measuring HIV neutralization in a luciferase reporter gene assay. Methods Mol. Biol. 485, 395-405 (2009).

109. Bomsel, M. Transcytosis of infectious human immunodeficiency virus across a tight human epithelial cell line barrier. Nat. Med. 3, 42-47 (1997). 